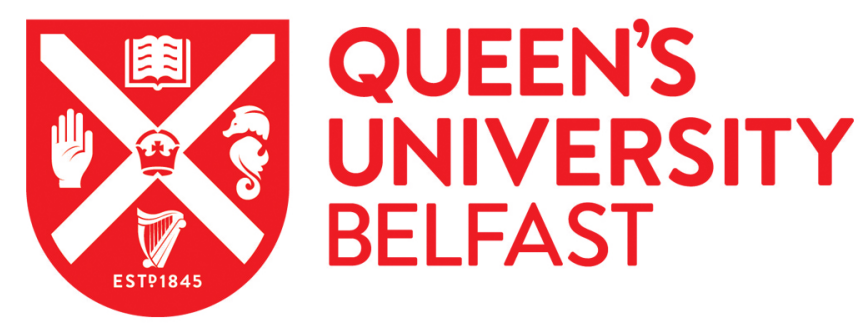

\title{
Representing financial data streams in digital simulations to support data flow design for a future Digital Twin
}

Murphy, A., Taylor, C., Acheson, C., Butterfield, J., Jin, Y., Higgins, P., Collins, R., \& Higgins, C. (2020).

Representing financial data streams in digital simulations to support data flow design for a future Digital Twin. Robotics and Computer-Integrated Manufacturing, 61, [101853]. https://doi.org/10.1016/j.rcim.2019.101853

Published in:

Robotics and Computer-Integrated Manufacturing

Document Version:

Peer reviewed version

Queen's University Belfast - Research Portal:

Link to publication record in Queen's University Belfast Research Portal

Publisher rights

Copyright 2019 Elsevier.

This manuscript is distributed under a Creative Commons Attribution-NonCommercial-NoDerivs License

(https://creativecommons.org/licenses/by-nc-nd/4.0/), which permits distribution and reproduction for non-commercial purposes, provided the author and source are cited.

\section{General rights}

Copyright for the publications made accessible via the Queen's University Belfast Research Portal is retained by the author(s) and / or other copyright owners and it is a condition of accessing these publications that users recognise and abide by the legal requirements associated with these rights.

Take down policy

The Research Portal is Queen's institutional repository that provides access to Queen's research output. Every effort has been made to ensure that content in the Research Portal does not infringe any person's rights, or applicable UK laws. If you discover content in the Research Portal that you believe breaches copyright or violates any law, please contact openaccess@qub.ac.uk. 


\title{
Representing Financial Data Streams in Digital Simulations to Support Data Flow Design for a Future Digital Twin
}

\author{
A. Murphy ${ }^{\mathrm{a},+}$, C. Taylor ${ }^{\mathrm{a}}$, C. Acheson ${ }^{\mathrm{a}}, \mathrm{J}$. Butterfield ${ }^{\mathrm{a}}$, Y. Jin ${ }^{\mathrm{a}}$, \\ P. Higgins ${ }^{\mathrm{b}}$, R. Collins ${ }^{\mathrm{b}}$, C. Higgins ${ }^{\mathrm{b}}$ \\ ${ }^{a}$ School of Mechanical and Aerospace Engineering, Queen's University Belfast, Ashby \\ Building, Belfast. Northern Ireland, U.K. BT9 5 AH \\ ${ }^{a}$ N.I. Technology Centre, Queen's University Belfast, Belfast, BT9 5HN \\ + Corresponding author: Tel.: +4428 9097 4095; E-mail: a.murphy@qub.ac.uk
}

\begin{abstract}
Discrete Event Simulations may be used to forecast detailed production system behaviour under future conditions and support better informed decision making. However, data beyond production metrics, e.g. financial information, is also necessary for most significant decisions. Herein a modelling approach is proposed and demonstrated based on simulating both production and financial transactions. The contribution of this paper is to represent the base production events as well as additional events which trigger financial transactions. The method is demonstrated for an idealised production business, employing Discrete Event Simulation and examining the impact of system labour arrangements on the business cash flow with a variable demand based on a normal probability distribution function (with distinct means and variances for each product). Based on the financial transactions a representation of a detail commercial scenario may be modelled alongside the production events. The presented studies identify the potential sensitivity of analysis to the volume and timing of transactions on accumulated accounting metrics such as profit. Additionally the paper illustrates how such a modelling approach can be used to characterise the system and
\end{abstract}


assess specific control strategies when both production and finance data streams are available.

Keywords: Industrial Internet of Things, Discrete Event Simulation; Factory Digital Twin; Financial metrics; Real time forecasting; Production demand; Labour resource planning.

\subsection{Introduction}

A significant volume of research has demonstrated the value of simulation to design and improve production systems [1-10, 47]. Much work has demonstrated the use of simulation to

quantify system behaviour with new or changed system layout or hardware, control or scheduling [48-50]. Methods such as Discrete Event Simulation (DES) enable complex process chains to be examined to understand bottlenecks, excess inventory, overproduction, etc. $[11-12,51]$. By representing a production system as a simulation model it is possible to examine in virtual scenarios how a real system might work under predefined conditions. The influence of key production characteristics, such as WIP or throughput can be readily examined during such virtual scenarios. A key weakness of the current state-of-the-art in this area is the lack of non-engineering metrics typically modelled. For decision makers the critical metrics are often not solely engineering but also financial, for example, profitability, return on investment, overhead cost [52]. However automatically generating financial metrics from simulation output production metrics is a non-trivial task [13, 14]. Moreover the nature of financial and production metrics are typically dissimilar in fidelity and interval. Thus this paper investigates the challenges of predicting both operational level production metrics along with financial metrics using a single modelling framework. This is achieved by focusing on system transactions, both production and financial, and modelling the physical production processes which link these together. A case study is used to develop and 
demonstrate the modelling approach. The case study represents an idealised production system and the finances and financial arrangements typically witnessed in small dedicated production businesses. The system is simulated using the commercial DES software QUEST and includes integrated spreadsheets to represent standard accounting practice. It is proposed that with such predictive modelling capability, based on physical processes and existing financial arrangements, future control strategies which autonomously prompt system interventions may be developed which monitor both production and finance data streams, i.e. a production system Digital Twin.

The following section, Section 2, presents a brief literature review. This is followed by a description of the case study (Section 3) and the proposed modelling approach (Section 4) before the case study results are presented (Section 5). The final section (Section 6) outlines the conclusions which can be drawn from the presented results.

\subsection{Literature review}

\subsection{Simulation}

Discrete Event Simulation (DES) may be used effectively to simulate a production system $[15,48,50-51]$, because its state may be represented as altering only at discrete points in time, e.g. when a component arrives at a workstation. A number of comprehensive, broad scope and focused review papers have been published which examine the use of DES in understanding and improving manufacturing systems [1-10]. These works have considered simulation software selection and evaluation [1-2]; manufacturing system design and operation [3-4]; scheduling and control [5-7]; system optimisation [8]; system maintenance [9]; and real-world applications considering manufacturing and business metrics [10]. 
Together these works provide an effective summary of progress in manufacturing modelling with DES over the last four decades. In reviewing their discussions and conclusions it is possible to identify repeating themes relevant to this work: flexible manufacturing systems and automated material handling systems have received the greatest attention, frequently only machines are modelled and labour assumed available, processes dominated by labour content have received less attention; predominantly what-if scenarios are considered and have been demonstrated to enable the understanding of the effect of production parameter changes on production output metrics; financial impact is frequently considered only indirectly through production metric such as throughput, cycle time, WIP etc.; recent works have also demonstrated DES successfully integrated with a wide range of non-engineering tools/models and algorithms.

Considering the generation of non-production data Johansson and Jackson [16] demonstrate DES is a tool that can be used to generate customized information for decision support. In this case study a production facility for Printed Circuit Boards was modelled and the generation of customized information and real time forecasting demonstrated. Spedding [17] models a semi-automated Printed Circuit Board assembly line demonstrating the use of DES and Activity Based Costing. Spedding concludes that the combination of cost modelling and simulation provide the potential for greater detail and the ability to account for the intrinsic variation of a dynamic manufacturing system. Sachidananda et al. [18] modelled a biopharmaceutical manufacturing system and a 50\% reduction in throughput time for a selected process, the paper investigated efficiency and cost benefits based on simulation output.

In general, the literature illustrates how procedures can be applied to improve a production system design via simulation focused on operational level production metrics. Research has also demonstrated instances of production simulations creating non-production 
data including cost estimates. To date there are no procedures or guidelines proposed on how DES may be used to routinely assess the influence of operational level production metrics on higher level financial metrics, or how to efficiently benchmark control strategies which include such financial metrics. Moreover, works to date have typically applied only cost modelling techniques which are a subset of the available financial assessment methods. Clearly simulation tools are available for the digital representation and simulation of production systems. Based on these software tools robust processes and workflows have been established to design and optimise production systems considering diverse objectives and constraints $[35,36]$. Recently however much attention has been given to creating digital representations which link to the physical production system and allow for real-time compensation and optimisation given real-world uncertainty and unpredictability [35, 53-54]. Kritzinger et al. [37] defines a Digital Model as a digital representation of an existing or planned physical system where there is no automated data exchange between the physical world and the digital representation. Much of the preceding references are within this domain. Kritzinger et al. [37] also defines a Digital Shadow when there exists an automated one-way data flow between the physical system and digital representations and a Digital Twin when there is a fully integrated and bidirectional flow of data between the physical system and the digital representations. There are significantly fewer examples of Digital Shadows and Digital Twins in the literature [37]. In this new domain early works have demonstrated appropriate geometric representation [38], usability of simulation modelling methods [39], modules to support decision making [35], product cell emulation for control verification [40], data exchange, modelling and storage [41, 42]. However, significant stated challenges in realising Digital Shadows and Digital Twins relate to the availability / acquisition of real-time and appropriate shopfloor data and open or standards for hardware/software architectures and interfaces [37, 38, 42, 43, 44]. To the authors best 
knowledge, no works have used simulation approaches, in the form of a Digital Model or Digital Shadow, to examine the data exchange requirements between the digital representation of a production system and its associated financial representation. This theme, using simulation tools to study data exchange requirements, is the focus of the research herein.

\subsection{Financial assessment methods}

In the production domain the tools available to engineering teams to provide financial assessment in support of operational decisions are typically based on costing methods [1920]. Typically such tools forecast product costs by utilising historical data to build relationships between production variables within the data and variable changes with the new or modified process. A key consideration to be taken into account when investigating these estimating methods is their ability to accurately incorporate all costs incurred in the manufacturing process [21-22]. A significant shortcoming of many methodologies is the inability to accurately allocate indirect costs. ABC (Activity Based Costing) is centred on the time and resource of each activity in the manufacturing process and distributes indirect cost in proportion to the activities performed [23]. Similarly, PCE (Parametric Cost Estimating) focuses on the cost drivers in the manufacturing process [24], developing relationships between product features and historical cost or expenditure figures. These approaches lack clarity for modelling indirect costs, for example support functions that may vary over time.

At the other end of the scale are the financial statements of the business. At this level metrics such as profit or loss are visible. There are two main statement types: a balance sheet presents a snapshot of the financial position of a business at a point in time, an income statement captures a business's financial performance over a period of time [25-26]. For 
either the snapshot or accumulated metrics these are significantly removed from individual production activities and constrained in their form due to regulations on financial reporting. However they do accurately incorporate the complete costs associated with production, including indirect costs.

\subsection{Summary}

Production environments have been modelled and a wide range of operational production data streams calculated. Such data streams could be used with standard costing methods to make financial predictions however such costing methods do not effectively represent indirect costs. Thus an approach is proposed in which financial behaviour is understood through the prediction of financial transactions associated with production e.g. monthly wage bills, raw material payments, rent/rates payments, equipment depreciation schedules, etc.. Such periodic transaction data may be used to populate financial statements (balance sheets, income statements [25-26]) and thereby represent financial behaviour. Thus herein an integrated simulation methodology will be developed and demonstrated focusing on production and financial transactions as the core data streams. The production transactions will then be used to calculate typical operational metrics, e.g. WIP, utilisation, etc.. The equivalent financial transactions will be used to perform standard accounting calculations for the creation of periodic income statements. Finally, as limited DES literature addresses production problems with high labour content the case study will be adjusted to represent a process chain dependent on labour and labour arrangement will be represented as a model variable. In summary there is limited literature on representing both detailed production and financial transactions using Discrete Event Simulation. Preceding literature in which costs are considered typically only reflect direct production cost and infer these by accumulated base 
production metrics such as the total labour consumed within the simulated period or the total number of machines required. The key innovation and major contribution of this paper is to represent the base production events as well as additional events which trigger financial transactions. Based on the financial transactions a representation of a detail commercial scenario may be modelled alongside the production events. In this way the calculation of financial metrics is not constrained by what is represented in the production simulation. Complete accounting methods may be linked to the represented financial transactions and thereby allow the inclusion of both direct and indirect costs associated with production. The case study is discussed next.

\subsection{Case study}

This section outlines the case study production problem. A modified problem from the literature is modelled (the P\&Q problem which was originally developed to demonstrate the theory of constraints [27]). Typically, the model assumes the processes as machining techniques that require limited labour input. In the literature a single operator is required to conduct each process and each operator works on only one process, Figure 1. As labour has been less frequently studied in the literature herein all processes (A, B, C, D) are assumed as tasks requiring full labour attention. Thus individual task setup times are incorporated into the process time and are assumed to be used for jig loading and fastener placement. However, the combined time (setup plus unit processing time) for each of the system processes (A, B, C, D) have been held approximately equivalent to the original batch processing times. This has ensured that the system bottleneck remains the same and the task of generating profit remains challenging. 
The system produces two products (P's and Q's). One unit each of materials 1 and 2 combined with one purchased part constitutes the process chain for product P. One unit each of Materials 2 and 3 constitutes the chain for product Q. Material 1 is processed by A, C and $\mathrm{D}$, Material 2 is processed by $\mathrm{B}, \mathrm{C}$ and $\mathrm{D}$ and Material 3 is processed by A, B and D. During process $\mathrm{D}$ product $\mathrm{Q}$ is made or the purchased part is added to create product $\mathrm{P}$. In the defined problem process B is a constraint. Output from the first two processes are stored in the Manufacturing Component Stores (MCS) until either process D is free, the other product specific component reaches the MCS or the purchased part store is replenished. The product is then assembled and stored in the Final Goods Stores (FGS) before being shipped.

The end user decision which is to be supported by the simulation case study relates to the definition of a labour arrangement and the evaluation of potential control strategies which can best satisfy the prescribed short term varying product demands while ensuring longer term production system profitability. The variable demand is based on a normal probability distribution function, with distinct means and variances for each product. Other probability distribution functions could be employed to describe the demand profile. However, within the case study analysis only a normal probability distribution function is considered and demonstrated. The labour arrangement options to be considered include fixed operators assigned to the individual work-stations (processes A, B, C, D), floating operators assigned to production zones comprising specific work-station combinations, operators assigned with the ability to work on any production process (A, B, C, or D), or a combination of the above.

\subsection{Methodology}


This section outlines the strategy employed to create appropriate operational data streams suitable for study and the use of these to calculate financial data streams. Additionally, given the volume of modelled variables (both production and financial) the section also presents the approach employed to initially verify the models and characterise and understand system sensitivity to individual variable values.

\subsection{Production case study}

To govern the production system in the simulation a Material Requirements Planning (MRP) approach is employed. A weekly sales demand is used to generate the backward schedule for the MRP. The assembly works orders are forecasted backwards from the sales demand dates and the operational works orders, the starting operations of the system, are generated by backward forecasting from the assembly works orders. The discrete event model, Figure 2, represents each process with its own workstation within three distinct production lines: Processes A and C within Production Line 1 (PL1), Processes B and C within PL2, processes A and B within PL3, and process D as the Final Assembly workstation (FA). No shared resources are modelled between the production lines. Along with the representation of the process flows and individual process stations the operators are also modelled within the simulation as individual resources. The operators are modelled with a maximum utilisation of $89 \%$ (to account for breaks etc.). Thus from the simulation individual operator value adding and non-value adding times are extractable.

\subsection{Financial data}


In order to model the financial behaviour associated with the production processes all activities resulting in financial transactions must be available from the simulation. Herein a prediction of an income statement which records the changes in financial position of a business over a defined period of time is of interest. The three main elements of an income statement are: Revenue - Income earned from trading; Gross profit - Revenue from trading less cost of goods sold (COGS); Net profit - Profit after all other income and expenses have been considered. From the production model the COGS can be calculated (including materials used to create goods sold and direct labour costs generated from the production of goods). Therefore, the model must represent the costs associated with the complete production system, i.e. the factory. Accordingly, the model not only includes the costs directly related to the production tasks (such as raw material and purchased part costs, direct labour costs) but also a wide and diverse range of costs associated with supporting and indirect activities. These include indirect overhead costs including rent and rates. In order to include these supporting and indirect financial variables and assemble these together with the production generated financial variables to create the income statement standard UK accounting practice is employed. The accounting practice calculations are codified within the MS Excel BV macros to allow the individual elements to be easily adjusted to represent a different accounting practice (i.e. say in a different country) or a change of the variables to represent a different business circumstance or different company. With regards labour cost absorption costing is used which assigns the costs accumulated during the production process to individual products. This approach also enables indirect costs such as variable overheads and fixed overhead to be added to the direct material costs and assigned to the individual products. Moreover, from the simulation WIP, MCS and FGS values are also available, describing not only the total system input and output with time but also the state of conversion at discrete time intervals. 
Figure 3 illustrates the modelled financial transactions, internal and external to the business. By recording the materials released into the simulation, the labour activity and machine activity it is then possible to feed a financial model representing a specific company financial arrangement (fixed and variable costs, debtor/creditor payment schedules, etc.) and to predict resultant cash-flow behaviour based on time varying production simulation results. Equations 1 to 4 describe the calculation of Cash flow (using absorption costing). Profit (or loss) is then calculated as the accumulation of cash flow over a defined period.

$$
\text { Cash flow }=\text { SALES }- \text { COGS }-\begin{array}{cc}
\text { Labour under } & - \text { Overhead under } \\
\text { recovery } & \text { recovery }
\end{array}
$$

COGS = Material costs + Labour recovered + Overheads recovered

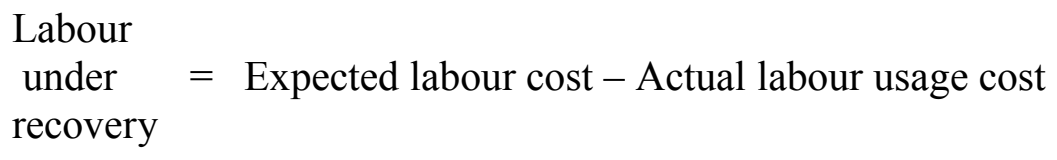

\footnotetext{
Overhead

under $=$ Expected overhead cost - Actual overhead usage cost recovery
}

The production and financial representations are combined together in a modelling framework which enables rapid analysis of the case study considering variation to the demand profile, the production system or the financial parameters. Figure 4 presents an overview of the modelling framework which uses MS Excel and VB macros along with QUEST simulations which directly read in data (for example works orders) and output data 
(for example raw material orders and final goods in store) to Excel worksheets. Thus Excel embedded macros are used to prepare the input data for the discrete event production simulations, initiate the simulations, then use the simulation output to define the full range of counterpart financial transactions for the relevant production transactions, before ultimately using the combined production and financial transactions to calculate the data required for income statement generation. This process may be completed in a single step for the complete time period of interest or completed in a series of partitions (for example in week increments) such that the production system parameters (for example labour arrangements) may be adjusted to better meet a particular set of production and financial objectives.

The main variables in the model are grouped into families and listed in Table 1. The cycle time inputs allow for the manipulation of the cycle time for each process. The model represents variable failures in the form of a time delay of 15 minutes occurring every 150 parts for each of the processes. There is a set 5\% rework value set within the overhead costing of the model. Labour is modelled as 3 or 4 operators with training for individual lines or all workstations. The noteworthy model simplifications and assumptions are: the model does not account for travel time between MCS and final assembly, and from final assembly to FGS. The raw material and purchased part prices are known and fixed, the P and Q selling prices are known and fixed. The standard cost of the input materials, the cost that is used for forecasts at the beginning of the time period, and the actual cost, the cost which is actually incurred, is assumed to be the same throughout. There are no delays relating to the purchased goods (purchased part and raw material).

\subsection{System verification and characterisation}


In order to verify that the production problem was modelled properly and the financial calculations coded correctly a series of verification steps where initially completed. These included iteratively building the model with increasing complexity and running deterministic simulations and comparing output against manually calculated answers. Output from the coded financial calculations was also subjected to scrutiny, including presentation to subject experts in accounting practice. For relevant robust verification methods and best practice, the reader is referred to references [45] and [46], which were used to guide the verification approach herein.

The complete system model contains a high number of interacting variables, Table 1, which will make difficult initial interpretation of the system behaviour. In a full factorial study all possible combinations of variables are systematically examined to understand the system behaviour. In a fractional factorial study a select number of combinations are studied to reduce computational effort but limit the loss of critical information [28]. Thus fractional factorial and Design of Experiment techniques [29-30] are initially use to screen for the significant variables, assess interactions between variables and quantify the influence of variables (ANOVA). The following section presents the case study results.

\subsection{Results}

Having formed a simulation of the production environment, its controlling MRP process and a framework to model financial transactions the system demand is the final input required. System demand is used to govern the assembled modelling framework and is calculated for each week of the simulation based on a predefined mean and standard deviation for each 
product (P's and Q's). This enables demand variability and general demand trends to be represented in the calculations.

\subsection{Understanding system behaviour}

Initially a series of predictions were performed to understand how the pure financial input variables influenced system profit. Each simulation started with the same initial condition and the same demand profile for 28 weeks (111 P's per week, 34 Q's per week). In addition the model was configured for batch processing of parts and each simulation given initially equal company financial arrangements (i.e. fixed costs (rent, rates, consumables, depreciation), variable costs (raw material, purchased part), payment schedules (debtor, creditor)), and equivalent individual process cycle times and process variability. An orthogonal array [28] was used to construct a series of simulation runs considering 5\% variation to the selling price of the P and Q products. ANOVA analysis was then undertaken on the simulation output to calculate the contribution to the predicted variation in Profit. P was found to contribute $90 \%$ and Q 10\%, demonstrating the selling price of the $\mathrm{P}$ was the dominant factor. This result is explained by the fact that the average weekly demand for Ps is approximately 3 times that for Qs.

A similar study was then preformed for raw material and purchased part costs, this time with $10 \%$ variation. The greatest percentage contribution was Material 2 at $59 \%$, followed by 36\% for Material 1 and 3\% for Material 3, Figure 5. This supports the finding of the previous result as Materials 1 and 2 form product $\mathrm{P}$ and therefore have the greatest effect 
on profit when manipulated. The ANOVA results also determined that there was no significant interaction between the raw material and purchased part costs, Figure 5.

A third study considering all the previous input variables varying by $10 \%$ was then undertaken. In this case the greatest percentage contribution was the selling price of product $\mathrm{P}$ at $81 \%$. It is much greater than the other factors as product Q contributed $8.2 \%$, Material 2 contributing $6.6 \%$ and Material 1 contributing 4\%. This illustrates, for equal percentage change, product selling price is more influential on Profit than material cost. This result is logical as the selling prices are greater in magnitude than the material costs.

A similar screening study was then undertaken to consider production inputs, Figure 6. The inputs used were: batch size (40 to 20 units), material cost (10\% variation), cycle times (10\% variation), scrap (5\% variation), breakdown (5\% variation), setup times (10 to 5 minutes), and labour type ( 3 man floating to 4 man fixed labour). Scrap contributed $80 \%$ to the variation of profit, while the raw material costs contributed $12 \%$. Scrap is the largest factor because every batch on each process experiences the scrap rate from a low value of 5\% to a high value of $10 \%$. All other factors contributed less than $3.36 \%$ each.

Having established an initial understanding of system behaviour a further set of parametric simulations were completed to assess the sensitivity of model output to demand variability. In each case a variable from Table 2 was parametrically changed and total profit monitored. Each simulation was run for 28 weeks with a variable product demand (P's: $\mu=111, \sigma=6$, Q's: $\mu=34, \sigma=6$ ). These simulations did not develop new understanding of the system behaviour but established that accumulated profit was sensitive to sales transactions within the final week of the simulation. For example Figure 7 illustrates a simple case examining variations in Setup Time. In this case decreasing Setup Time from 10 to 0 minutes has no impact on the predicted profit. However it clearly results in parts making it to the FGS 
but not being shipped in the period. To address this weakness it is possible to represent the value of complete or incomplete work in the manufacturing system using a Weighted Asset Value (WAV) calculation, Equation 4 to 6, [31-34]. Figure 7 illustrates how the addition of a WAV for the units in the FGS may better represent the effectiveness of the manufacturing system in the period. A second approach to reduce the sensitivity is to consider cash flow as the variable and only calculate profit over extended time periods connected to the financial year. The extended period will result in larger profit values and will smooth the impact of individual transactions at the end of the reporting period.

$$
\begin{gathered}
\begin{array}{c}
\text { Conversion } \\
\text { period }(\text { days })
\end{array}=\quad \frac{\text { Inventory }}{\text { COGS }} \times \text { Number of working days } \\
\text { Completion ratio }=\frac{\text { Inventory conversion period }- \text { Asset conversion period }}{\text { Inventory conversion period }} \\
W A V_{(F G S)}=\text { Asset }_{(F G S)} \times \text { Expected Profit } \times \text { Completion ratio }(F G S)
\end{gathered}
$$

These initial results demonstrate that a DOE approach can identify the critical variables and potential variable interactions. Moreover there is clear evidence that work in the system (either complete or incomplete) at the end of a reporting period needs to be considered for accumulated accounting metrics such as profit

\subsection{Impact of labour arrangements with variable demand with zero growth}


Based on the preceding results and to best represent Lean production the model was reconfigured to represent one piece flow and a stock cap was placed on the MCS for parts 1, 2 and 3 at a maximum capacity of 10 components. A series of four simulations then were undertaken with different labour arrangements. Each simulation was run for 104 weeks with the same initial condition and the same demand profile (P demand: $\mu=151, \sigma=6$, Q demand: $\mu=74, \sigma=6)$. As before each simulation has equal company financial arrangements, equivalent individual process cycle times and process variability. Each simulation output is summarised in the following section illustrating the data streams initially available for analysis.

\subsubsection{Dedicated operators on each work-station}

Figure 8 presents the key production and financial data streams: part (a) illustrates workstation utilisation. In this case operator and work-station utilisation is the same thus PL1, PL2, PL3 and FA average utilisation is $61 \%, 30 \%, 89 \%$ and $26 \%$ respectively; (b) documents the units produced along with the units demanded; (c) plots the resulting system finances including the cash flow. Examining Figure $8(a)$ the average utilisation in PL2 is $89 \%$ representing the upper bound achievable with the modelled operator breaks. FA operator utilisation is only $26 \%$ and this represents the difference in maximum capacity of PL2 and this downstream process. Average utilisation in PL1 and PL3 is 61\% and 30\% respectively; with these utilisation levels a result of the FA constrained capacity and the presence of a buffer limit at the end of these lines. Thus as before process B on PL2 is the system bottleneck. Examining Figure 8(b) the average produced and demanded units are the same, however closer inspection reveals a number of weekly instances of over and under production. Across the 104 weeks, there were 13 weeks with unsatisfied demand for product $\mathrm{P}$ and 5 for product Q. The financial predictions are plotted in Figure 8(c). In general, the 
cash flow has a negative trend with a final value of $£(71,279)$ at week 104 . This reflects a high level of Labour and Overhead under recovery due to the low utilisation of both the workstations and operators in PL1, PL3 and FA, but also the reduced sales income resulting from the unsatisfied demand for both products.

\subsubsection{Shared operator on PL1 and PL3 (three dedicated operators)}

As in the first simulation case PL2 and FA have dedicated operators but in this simulation case PL1 and PL3 have a single shared operator. Figure 9 presents the key production and financial data streams: part (a) illustrates work-station utilisation; (b) documents the units produced along with the units demanded; (c) plots the resulting system finances including the cash flow. In this case operator average utilisation for FA, PL1\&PL3 and PL2 is $23 \%, 88 \%$, and $89 \%$ respectively. Examining Figure 9(a) the average utilisation of PL2 and its operator remains high (on average 78\%). Average utilisation of work-stations PL 1 and PL3 remain low (55\% and $27 \%$ respectively) with their combined operator utilisation now $89 \%$ (representing the upper bound achievable with the modelled operator breaks). Thus the shared operator on PL1 and PL3 appears to be a new system bottleneck. This is further evidenced by the reduction in system output. Across the period weekly output for Ps and Qs are $11 \%$ and $10 \%$ lower than the demand rate (Figure $9(\mathrm{~b})$ ). Demand of product $\mathrm{P}$ is unsatisfied for all 104 weeks and for 73 weeks for product Q. However, the financial performance in Figure 9(c) presents a positive trending cash flow across the period with a final cash flow statement at week 104 of $£ 98,915$. Examining in detail the individual finance elements the impact of a lower level of Labour and Overhead under recovery, due to the higher utilisation of the operators, offsets the reduction in the number of goods sold. 


\subsubsection{Three floating operators}

In the first two simulations the operators are assigned to individual production zones or workstations. In this simulation three floating operators are modelled who can work on any production zone or work-station. The fixed and variable costs associated with labour were also modified to account for higher salary and training requirements. Figure 10 presents the key production and financial data streams. In this case operator average utilisation is $87 \%$, $75 \%$ and $46 \%$. Line and work-station utilisations have increased by between 3 and $6 \%$ over the preceding case with 3 operators (Section 5.2.2) with the same rank order of average utilisation with PL2 with the highest level and FA with the lowest. With respect to output, Figure 9(b), output again fall short of demand with unsatisfied demand in a total of 48 and 26 weeks for products P and Q respectively. Examining the financial performance, Figure 10(c), a positive trending cash flow is predicted with a final cash flow statement at week 104 of $£$ 121,948. Again the improved Labour and Overhead under recovery with higher utilisation and the greater volume of sales results in the positive cash flow and its final value.

\subsubsection{Summary}

Table 2 summarises the key simulation results. Four dedicated operators is the approach which best satisfies the demand rate but produces a generally negative cash flow. The next closest to the demand is three floating operators which achieved $3 \%$ less output for both products than the required demand rate but yielded the highest cash flow value at the end of the runtime due to the higher operator utilisation and product output. None of the operator arrangements examined completely satisfies the specified demand thus a final simulation is

undertaken with four floating operators. Figure 11 presents the key production and financial data streams. This arrangement of labour satisfies the specified demand with no unsatisfied 
demand weeks. However this arrangement consistently overproduces Ps and Qs each week and ultimately results in the largest negative final cash flow statement at week 104 of $£$ $(233,496)$, Table 2 . Although the system is arranged for one piece flow and production buffers set to minimise the opportunity for WIP to build up uncontrolled in the system there is no buffer limit on the FGS. Figure 12 presents FGS inventory costs and the clear overproduction for the system throughout the simulation period. Thus the challenge is to resource the production system to match the demand without overproduction. Doing this with the minimum number of operators will minimise the Labour and Overhead under recovery and thus maximise the final cash flow position. Having identified the key system characteristics and the critical production and financial metrics which dictate a positive or negative cash flow the following section will examine the modelling of system behaviour when there is a longer term trend in demand.

\subsection{Impact of labour arrangements with variable demand with positive demand growth}

The demand from the preceding simulation was modified to represent the same variability but with an underlying growth trend for both products with a demand increase per week of $0.1 \%$, reaching an increase of $10.3 \%$ after the 104 week period. Two initial simulations with 3 and 4 floating operators where considered first. Table 3 summarises the key simulation results. The output from the three operator configuration cannot satisfy the increasing demand due to an operator bottleneck, as identified in Section 5.1.3 with an operator working with an average utilisation of $87 \%$, principally on PL2. The four operator configuration has no late deliveries across the simulation period but the systems output exceeds the demand and results in a negative cash flow. Thus switching between a three and a four operator configuration is required to match the demand without overproduction. Doing this with the minimum number 
of operators will minimise the Labour and Overhead under recovery and thus maximise the final cash flow position. Therefore it confirms that the key system characteristics to monitor is associated with demand vs. production or FGS stock level or FGS stock variation, and the key system characteristic to be controlled is the number of floating operators.

Thus a series of simulations where run to assess strategies to monitor individually the FGS buffer level, variation of the FGS buffer level, and variation between production and demand level. Each strategy was developed to remove any unsatisfied demand and limit overproduction, by adding or removing the fourth operator. Table 4 summarises the simulation results and Figure 13 presents the resulting system cash flow. Of the few examined strategies the best performing in terms of cash flow involves monitoring the variation between production and demand in the preceding two weeks. If demand is greater than production for either Ps or Qs in the preceding two weeks the fourth operator is utilised in the subsequent week. This approach does not result in the lowest average level of FGS stock for the examined cases but does result in the lowest total period of 4 operator production - whilst also satisfying the demand. In turn due to the better Labour and Overhead under recovery with 3 operator versus 4 operator production the simulation results generate the best cash flow. However, more important than this single result is the demonstrated ability to assess control strategies by quantifying their impact on both satisfying a varying demand as well as the production system overall financial performance, in this case cash flow.

\subsection{Conclusions}


Limited research exists on the use of simulations for the generation of coupled production and financial data streams. Herein an approach is proposed and demonstrated to model production and financial transactions based on a discrete event factory model. The key innovation is the demonstration of the modelling of additional events, which trigger financial transactions, which effectively permits in-depth financial scenarios to be considered alongside the shopfloor production events.

An idealised production system and business was modelled and both operational production behaviour and standard accounting metrics predicted for a range of scenarios. The method was demonstrated by considering the impact of system labour arrangements on the business cash flow with a variable product demand. The case study simulations demonstrate the use of the method to support the identification of a labour arrangement ( 3 floating operators) and the most promising control strategy (monitoring both demand and production in preceding weeks) which would best satisfy the prescribed product demands and ensure system profitability. Given the volume of possible production and financial variables the paper also demonstrated the use of DOE methods to initially characterise the behaviour of a modelled system. The study also identified the potential for the volume or the timing of transactions to make challenging the interpretation of accumulated metrics such as profit. It is demonstrated that work in the system (either complete or incomplete) at the end of the reporting periods may influence accumulated accounting metrics, with shorter reporting periods being more sensitive to this effect. Having demonstrated how such modelling can enable assessment of specific production scenarios the approach was applied to assess the performance of a number of simple control strategies. The approach demonstrated the basic capability for simulation based control where real time production and financial data can be used as base conditions for future state prediction, again in both the production and finance domains. 
Future work should demonstrate how the identified data streams can be automatically linked between the physical system and the conceived digital representation. In the first instance a Digital Shadow could be used for system emulation, allowing the optimisation and verification of appropriate control policies. Ultimately further work is required to formulate and demonstrate robust approaches for bidirectional data flow, and thereby enable the full benefits of a Digital Twin.

\section{Acknowledgment}

This work was supported technically by the Northern Ireland Technology Centre and Value Flow Consulting Ltd. The authors are also grateful to the Centre for Intelligent Autonomous Manufacturing Systems (i-AMS) at Queen's University Belfast for hosting and supporting the research.

\section{References}

[1] J. Nikoukaran, R. J. Paul. Software selection for simulation in manufacturing: a review. Simulation Practice and Theory, Vol. 7, pp. 1-14, 1999

[2] Y. Alomair, I. Ahmad, A. Alghamdi. A Review of Evaluation Methods and Techniques for Simulation Packages, Procedia Computer Science, Volume 62, 2015, Pages 249256, ISSN 1877-0509, http://dx.doi.org/10.1016/j.procs.2015.08.447.

[3] Negahban, A., J. S. Smith. Simulation for Manufacturing System Design and Operation: Literature Review and Analysis. Journal of Manufacturing Systems, Vol. 33 (2), pp. 241-261, 2014 doi:10.1016/j.jmsy.2013.12.007. 
[4] J.S. Smith. Survey on the use of simulation for manufacturing system design and operation. Journal of Manufacturing Systems, Vol. 22(2), pp. 157-71, 2003

[5] F.T.S. Chan, H.K. Chan, H.C.W. Lau. The state of the art in simulation study on FMS scheduling: a comprehensive survey. The International Journal of Advanced Manufacturing Technology, Vol. 19(11), pp. 830-49, 2002

[6] F.T.S. Chan, H.K. Chan. A comprehensive survey and future trend of simulation study on FMS scheduling. Journal of Intelligent Manufacturing, Vol. 15(1), pp. 87-102, 2004

[7] C.S. Shukla, F.F. Chen. The state of the art in intelligent real time FMS control: a comprehensive survey. Journal of Intelligent Manufacturing, Vol. 7, n6, pp. 441-455, 1996

[8] N. Prajapat, A. Tiwari. A review of assembly optimisation applications using discrete event simulation. International Journal of Computer Integrated Manufacturing, Volume 30, 2017 - Issue 2-3, Pages 215-228, 2017 doi: 10.1080/0951192X.2016.1145812

[9] A. Alrabghi, A. Tiwari. State of the Art in Simulation-Based Optimisation for Maintenance Systems. Computers \& Industrial Engineering, Vol. 82, pp. 167-182, 2015. doi:10.1016/j.cie.2014.12.022.

[10] M. Jahangirian, T. Eldabi, A. Naseer, L. K. Stergioulas, and T. Young. Simulation in Manufacturing and Business: A Review. European Journal of Operational Research Vol. 203(1), pp. 1-13, 2010. doi:10.1016/j.ejor.2009.06.004.

[11] J. Banks. Handbook of Simulation: Principles, Methodology, Advances, Applications, and Practice: Modelling, Estimation and Control. Wiley-Interscience publication, 1998

[12] J. Banks, J.S. Carson, B.L. Nelson. Discrete-event System Simulation. Prentice Hall, 2010

[13] C. Acheson, D. Mackle, A. Murphy, J. Butterfield, P. Higgins, R. Collins, C. Higgins, J. Darlington, R. Tame. Using Design of Experiments To Define Factory Simulations 
for Manufacturing Investment Decisions. Paper presented at 34th International Manufacturing Conference, Sligo, Ireland, 2017

[14] C. Acheson, D. Mackle, A. Murphy, J. Butterfield, P. Higgins, R. Collins, C. Higgins, J. Darlington, R. Tame. Integrating Financial Metrics with Production Simulation Models. Paper presented at $15^{\text {th }}$ International Conference on Manufacturing Research, London, United Kingdom, 2017

[15] A.M. Law, W.D. Kelton. Simulation Modeling \& Analysis (2 ${ }^{\text {nd }}$ ed). McGraw·HiII, 1991

[16] M. Jackson, C. Johansson. Real Time Discrete Event Simulation of a PCB Production System for Operational Support. in: S. Andradbttir, K.J. Healy, D.H. Withers, B.L. Nelson (Eds.), 1997 Winter Simul. Conf., 1997: pp. 832-837

[17] T.A. Spedding, G.Q. Sun. Application of discrete event simulation to the activity based costing of manufacturing systems. International Journal of Production Economics, Vol. 58, pp. 289-301, 1999

[18] M. Sachidananda, J. Erkoyuncu, D. Steenstra, S. Michalska, Discrete Event Simulation Modelling for Dynamic Decision Making in Biopharmaceutical Manufacturing. Procedia CIRP, Vol. 49, pp. 39-44, 2016

[19] R. Curran, S. Raghunathan, M. Price. Review of aerospace engineering cost modelling: The genetic causal approach, Progress in Aerospace Sciences. Vol. 40, pp. 487-534, 2004

[20] A. Niazi, J.S. Dai, S. Balabani, L. Seneviratne. Product Cost Estimation: Technique Classification and Methodology Review, Journal of Manufacturing Science and Engineering, Vol. 128(2), pp. 563-575, 2005

[21] M. Mullan, A. Murphy, D. Quinn, M. Price, J. Butterfield, S. Cowan, S. McElroy, P. Hawthorne, S. Robertson. Modelling lay-up automation and production rate interaction 
on the cost of large stiffened panel components. The Aeronautical Journal, Vol. 118(1201), pp. 275-296, 2014

[22] P. Watson, R. Curran, A. Murphy, S. Cowan. Cost Estimation of Machined Parts within an Aerospace Supply Chain. Concurrent Engineering Research and Applications, Vol. 14(1), pp. 17-26, 2006

[23] International Accounting Standards Board. IAS 1: Presentation of Financial Statements. 2007

[24] International Accounting Standards Board. IAS 2: Inventories. 2012

[25] J. Darlington, K. Mackle. Cost Accounting: Public Enemy Number One to Productivity. Paper Presented at Sapics 35th Annual Conference \& Exhibition, June 2013, South Africa. ISBN 978-0-620-56523-3

[26] T. Uzun Kocamiş, Lean Accounting Method for Reduction in Production Costs in Companies. International journal of business, social and scientific research, Vol. 6, No. 9(1), pp. 6-13, 2015.

[27] Youngman DKJ. A Guide to Implementing the Theory of Constraints (TOC) [Internet]. Available from: http://www.dbrmfg.co.nz/Overview Introduction.htm

[28] R.F. Gunst, R.L. Mason. Fractional factorial design. Wiley Interdisciplinary Reviews Computational Statistics, Vol. 1, pp. 234-244, 2009

[29] D.C. Montgomery. Design and Analysis of Experiments ( $8^{\text {th }}$ ed.). John Wiley \& Sons, 2012

[30] R.K. Roy. Design of experiments using the Taguchi approach: 16 steps to product and process improvement. Wiley, 2001

[31] J.A. Gentry. State of the Art of Short-Run Financial Management. Financial Management, Vol. 41(17), pp. 41-57, 1988 
[32] V.D. Richards, E.J. Laughlin. A Cash Conversion Cycle Approach to Liquidity Analysis. Financial Management, Vol. 9(1), pp. 32-38, 1980

[33] Y.-J. Wang. Liquidity management, operating performance, and corporate value: evidence from Japan and Taiwan. Journal of Multinational Financial Management, Vol. 12, pp. $159-169,2002$

[34] J.A. Gentry, R. Vaidyanathan, H.W. Lee. A Weighted Cash Conversion Cycle. Financial Management Vol. 19, No. 1, 1990

[35] N. Kousi, C. Gkournelos, S. Aivaliotis, C. Giannoulis, G. Michalos, S. Makris. Digital twin for adaptation of robots' behavior in flexible robotic assembly lines. Procedia Manufacturing, Volume 28, Pages 121-126, 2019

[36] G. Michalos, A. Fysikopoulos, S. Makris, D. Mourtzis, G. Chryssolouris. Multi criteria assembly line design and configuration - An automotive case study. CIRP Journal of Manufacturing Science and Technology, Volume 9, Pages 69-87, 2015

[37] W. Kritzinger, M. Karner, G. Traar, J. Henjes, W. Sihn. Digital Twin in manufacturing: A categorical literature review and classification. IFAC-Papers On Line, Volume 51, Issue 11, Pages 1016-1022, 2018, 10.1016/j.ifacol.2018.08.474

[38] M. Lohtander, N. Ahonen, M. Lanz, J. Ratava, J. Kaakkunen. Micro Manufacturing Unit and the Corresponding 3D-Model for the Digital Twin. Procedia Manufacturing, Volume 25, Pages 55-61, 2018

[39] S. Boschert, R. Rosen. Digital Twin-The Simulation Aspect. In: Hehenberger P., Bradley D. (eds) Mechatronic Futures. Springer, Cham 2016, 10.1007/978-3-31932156-1_5

[40] D. Gyulai, A. Pfeiffer, B. Kádár, L. Monostori. Simulation-based Production Planning and Execution Control for Reconfigurable Assembly Cells. Procedia CIRP, Volume 57, Pages 445-450, 2016 
[41] G. N. Schroeder, C. Steinmetz, C. E. Pereira, D. B. Espindola. Digital Twin Data Modeling with AutomationML and a Communication Methodology for Data Exchange. IFAC-Papers On Line, Volume 49, Issue 30, Pages 12-17, 2016

[42] J. Um, S. Weyer, F. Quint. Plug-and-Simulate within Modular Assembly Line enabled by Digital Twins and the use of AutomationML. IFAC-Papers On Line, Volume 50, Issue 1, Pages 15904-15909, 2017

[43] T. H.-J. Uhlemann, C. Lehmann, R. Steinhilper. The Digital Twin: Realizing the Cyber-Physical Production System for Industry 4.0. Procedia CIRP, Volume 61, Pages $335-340,2017$

[44] Performance assessment of production systems with mobile robots", (CIRP CMS 2015), Procedia CIRP, 48th CIRP Conference on Manufacturing Systems, 24- 26 June, Naples, Italy Volume 36, pp.195-200 (2015)

[45] R.G. Sargent. Verification and Validation of Simulation Models. Proceedings of the 2007 Winter Simulation Conference, eds. S. G. Henderson, B. Biller, M.-H. Hsieh, J. Shortle, J. D. Tew, and R. R. Barton, Washington, DC, Dec. 9-12, pp. 124-137, 2007

[46] F. Giannasi, P. Lovett, A.N. Godwin. Enhancing confidence in discrete event simulations. Computers in Industry, Volume 44, Issue 2, Pp. 141-157, 2001

[47] H. Nylund, P.H. Andersson. Simulation of service-oriented and distributed manufacturing systems. Robotics and Computer-Integrated Manufacturing, Vol. 26, Issue 6, pp. 622-628, 2010

[48] Q. Hao, W. Shen. Implementing a hybrid simulation model for a Kanban-based material handling system. Robotics and Computer-Integrated Manufacturing, Vol. 24, Issue 5, pp. 635-646, 2008 
[49] J.T. Lin, F.K. Wang, Y.M. Chang. A hybrid push/pull-dispatching rule for a photobay in a 300mm wafer fab. Robotics and Computer-Integrated Manufacturing, Vol. 22, Issue 1, pp. 47-55, 2006

[50] D. Creighton, S. Nahavandi. Application of discrete event simulation for robust system design of a melt facility. Robotics and Computer-Integrated Manufacturing, Vol. 19, Issue 6, pp. 469-477, 2003

[51] J-H. Cha, M-I. Roh, K-Y. Lee. Integrated simulation framework for the process planning of ships and offshore structures. Robotics and Computer-Integrated Manufacturing, Vol. 26, Issue 5, pp. 430-453, 2010

[52] M.M. Ahmad, N. Dhafr. Establishing and improving manufacturing performance measures. Robotics and Computer-Integrated Manufacturing, Vol. 18, Issues 3-4, pp. $171-176,2002$

[53] Y. Lu, C. Liu, K. I-K. Wang, H. Huang, X. Xu. Digital Twin-driven smart manufacturing: Connotation, reference model, applications and research issues. Robotics and Computer-Integrated Manufacturing, Vol. 61, 101837, 2020

[54] Y. Lu, X. Xu. Cloud-based manufacturing equipment and big data analytics to enable on-demand manufacturing services. Robotics and Computer-Integrated Manufacturing, Vol. 57, pp. 92-102, 2019 


\section{Tables}

Table 1. Simulation variables grouped into families.

\begin{tabular}{|c|c|c|c|}
\hline Labour & Financial & Process & Variation \\
\hline Number of operators & $\begin{array}{l}\text { Standard cost of each raw material } \\
\text { and purchased part }\end{array}$ & Individual process cycle times & Process failure percentage \\
\hline $\begin{array}{l}\text { Operator training (for individual } \\
\text { lines or all workstations) }\end{array}$ & $\begin{array}{l}\text { Amount of each raw material } \\
\text { purchased per week }\end{array}$ & Stock cap on stores (MCS, FGS) & $\begin{array}{l}\text { Setup times for each part on each } \\
\text { process }\end{array}$ \\
\hline \multirow[t]{4}{*}{$\begin{array}{l}\text { Operator breaks (UK legal worker } \\
\text { breaks are modelled) }\end{array}$} & $\mathrm{P}$ and $\mathrm{Q}$ selling prices & $\begin{array}{l}\text { Amount of each raw material } \\
\text { purchased }\end{array}$ & $\begin{array}{l}\text { Scrap rate for each part on each } \\
\text { process }\end{array}$ \\
\hline & Wages and salaries & Purchased part batch size & \\
\hline & Depreciation & Batch size and transfer batch size & \\
\hline & Rent and rates per week & & \\
\hline
\end{tabular}


Table 2. Simulation result summary.

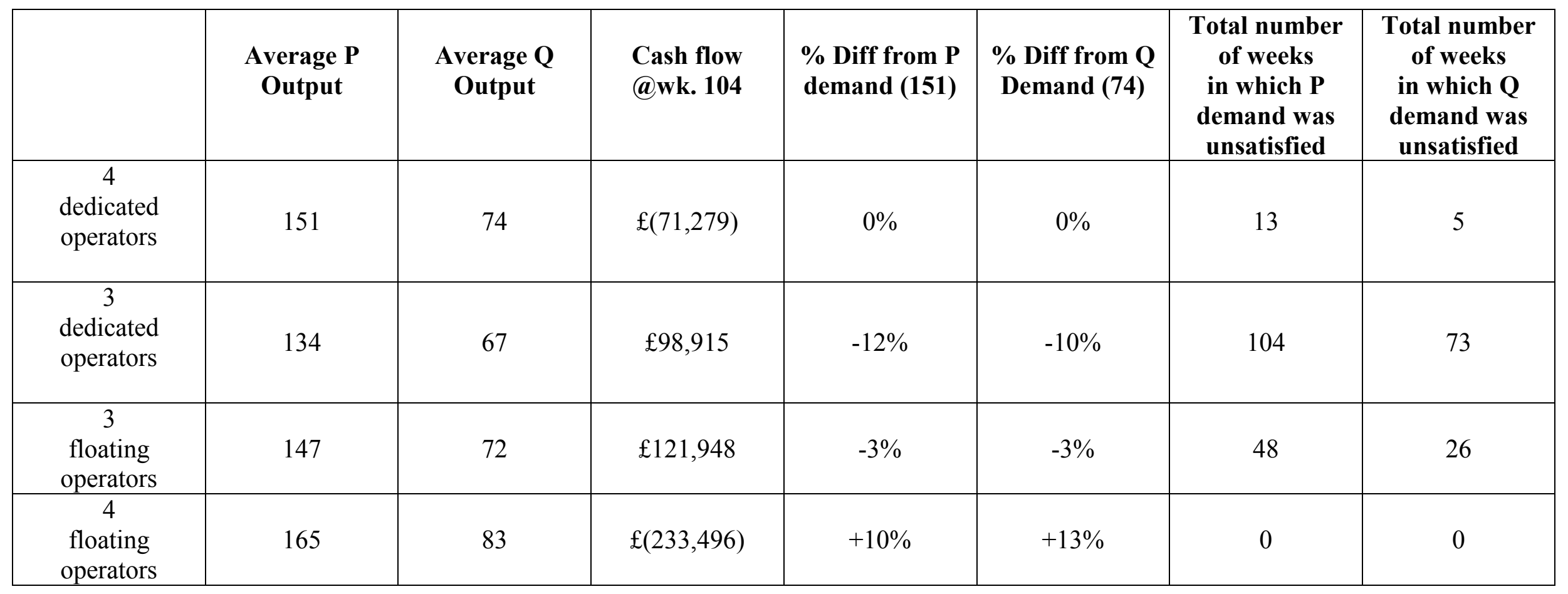


Table 3. Three and four floating operators with positively trending demand.

\begin{tabular}{|c|c|c|c|c|c|}
\hline & $\begin{array}{c}\text { Average } \\
\text { P } \\
\text { Output }\end{array}$ & $\begin{array}{c}\text { Average } \\
\text { Q } \\
\text { Output }\end{array}$ & $\begin{array}{c}\text { Total } \\
\text { Cash flow } \\
\text { awk. 104 } \\
\text { number of } \\
\text { weeks } \\
\text { in which P } \\
\text { demand was } \\
\text { unsatisfied }\end{array}$ & $\begin{array}{c}\text { Total } \\
\text { number of } \\
\text { weeks } \\
\text { in which Q } \\
\text { demand was } \\
\text { unsatisfied }\end{array}$ \\
\hline $\begin{array}{c}3 \\
\text { floating } \\
\text { operators }\end{array}$ & 147 & 72 & $£ 121,948$ & 89 & 59 \\
\hline $\begin{array}{c}4 \\
\text { floating } \\
\text { operators }\end{array}$ & 165 & 84 & $£(121,092)$ & 0 & 0 \\
\hline
\end{tabular}


Table 4. FGS stock level and late deliveries control simulation results.

\begin{tabular}{|c|c|c|c|c|c|}
\hline & $\begin{array}{l}\text { Average } \\
\text { P } \\
\text { Output }\end{array}$ & $\begin{array}{l}\text { Average } \\
\text { Q } \\
\text { Output }\end{array}$ & $\begin{array}{l}\text { Cash flow } \\
\text { @wk. } 104\end{array}$ & $\begin{array}{c}\text { Total number of } \\
\text { weeks } \\
\text { in which } P \text { demand } \\
\text { was unsatisfied } \\
\end{array}$ & $\begin{array}{c}\text { Total number of } \\
\text { weeks } \\
\text { in which } Q \text { demand } \\
\text { was unsatisfied } \\
\end{array}$ \\
\hline $\begin{array}{l}\text { FGS buffer limit - } 25 \% \text { of preceding } \\
\text { week demand (for both Ps \& Qs) }\end{array}$ & 159 & 81 & $£ 11,281$ & 3 & 0 \\
\hline $\begin{array}{l}\text { One week of reducing stock in FGS } \\
\text { (either Ps or Qs) }\end{array}$ & 158 & 80 & $£ 21,856$ & 13 & 0 \\
\hline $\begin{array}{l}\text { Demand greater than the production of } \\
\text { both the last two preceding weeks (either } \\
\text { Ps or Qs) }\end{array}$ & 157 & 78 & $£ 62,236$ & 34 & 0 \\
\hline $\begin{array}{l}\text { Demand greater than the production of } \\
\text { the preceding week (either Ps or Qs) }\end{array}$ & 159 & 80 & $£ 25,067$ & 0 & 0 \\
\hline
\end{tabular}


Figures

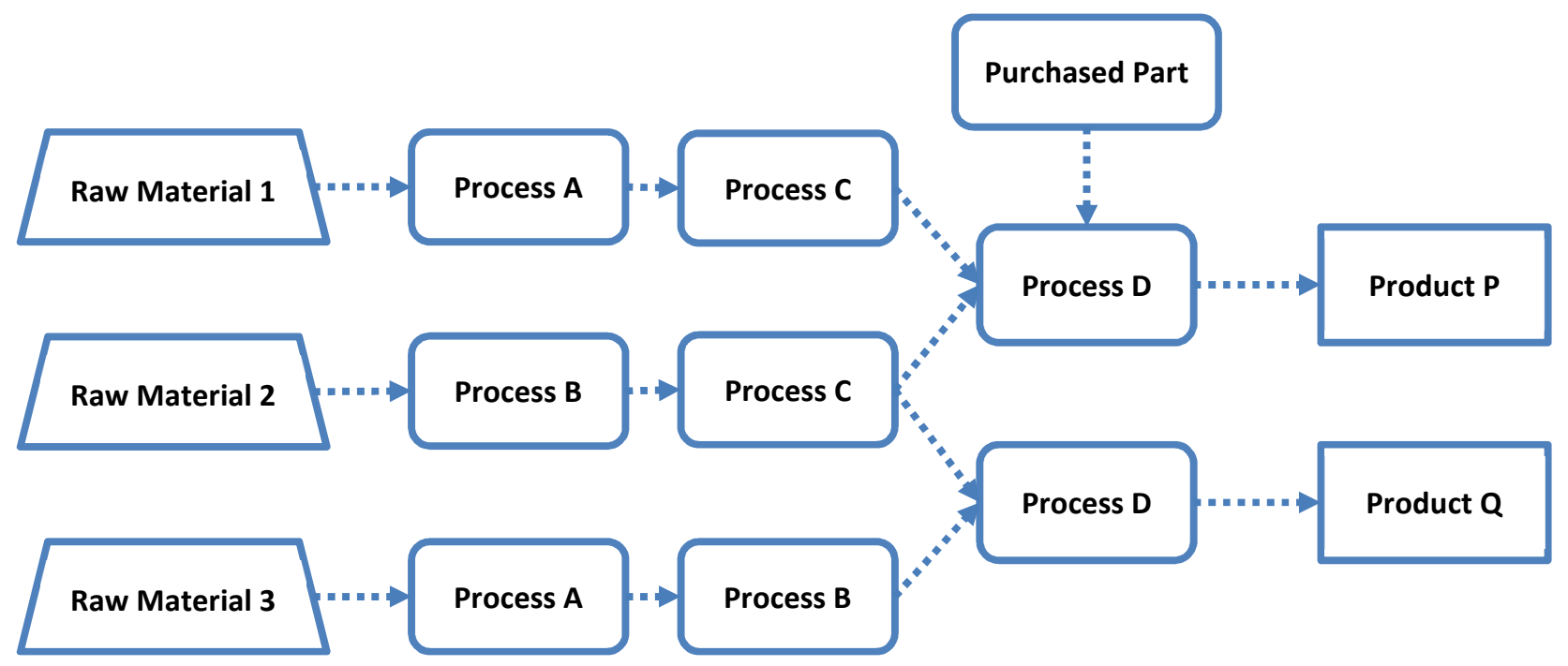

Figure 1 - Case study production arrangement (based on the P\&Q problem).

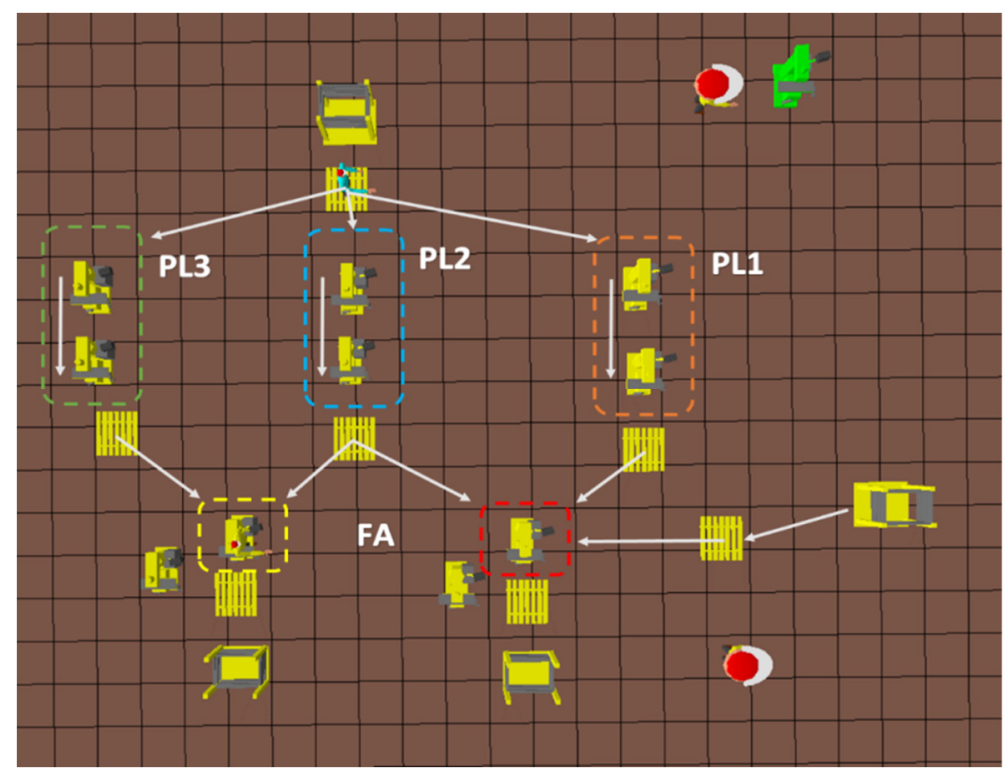

Figure 2 - Initial production simulation model. 


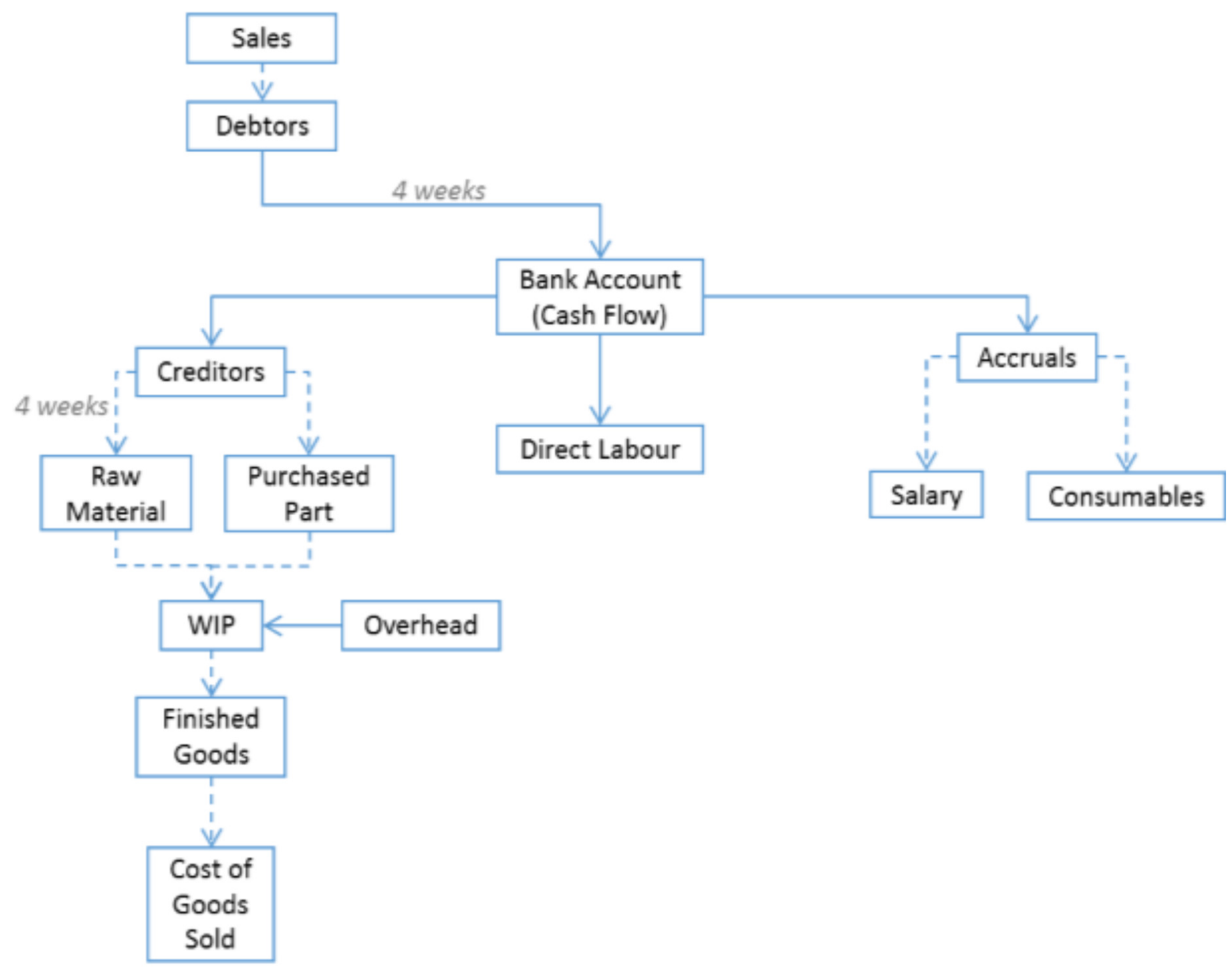

Figure 3 - Initial financial simulation model. 


\section{System}

performance

Production and financial data

for total simulation period

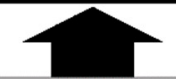

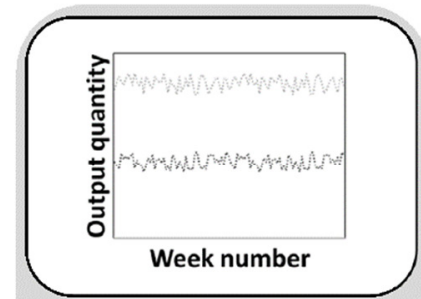

Demand profile for period

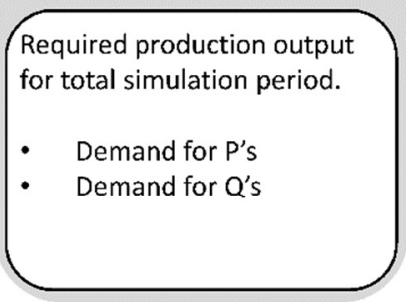

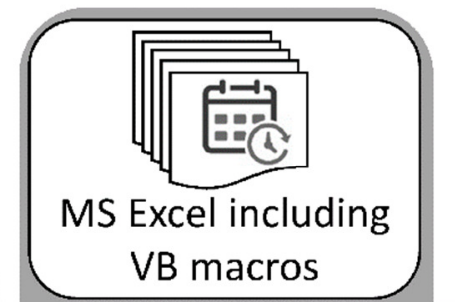

Material

Requirements Planning

Schedule calculation for partition of total period.

Output:

- Assembly works orders

- Operational works orders

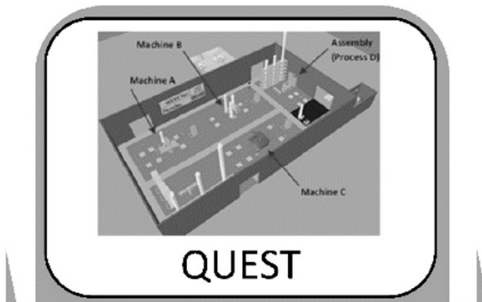

Discrete Event Simulation

Production transaction calculation for partition.

Output:

- Production transactions

- Production out

resource consumption.

\section{System labour arrangement}

MS Excel including VB macros

Financial system simulation

Calculation of financial

transactions including those directly and indirectly related

to production transactions.

Output:

- Financial transactions

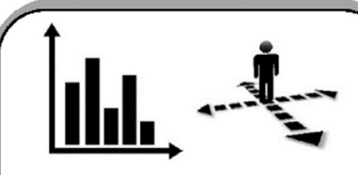

MS Excel including VB macros

System monitoring \& control

\section{Calculation of accumulated}

production and financial

metrics for simulated period.

Output:

- Income statement

- Updated control policies

for following time partition

Figure 3 - Architecture of the modelling framework. 


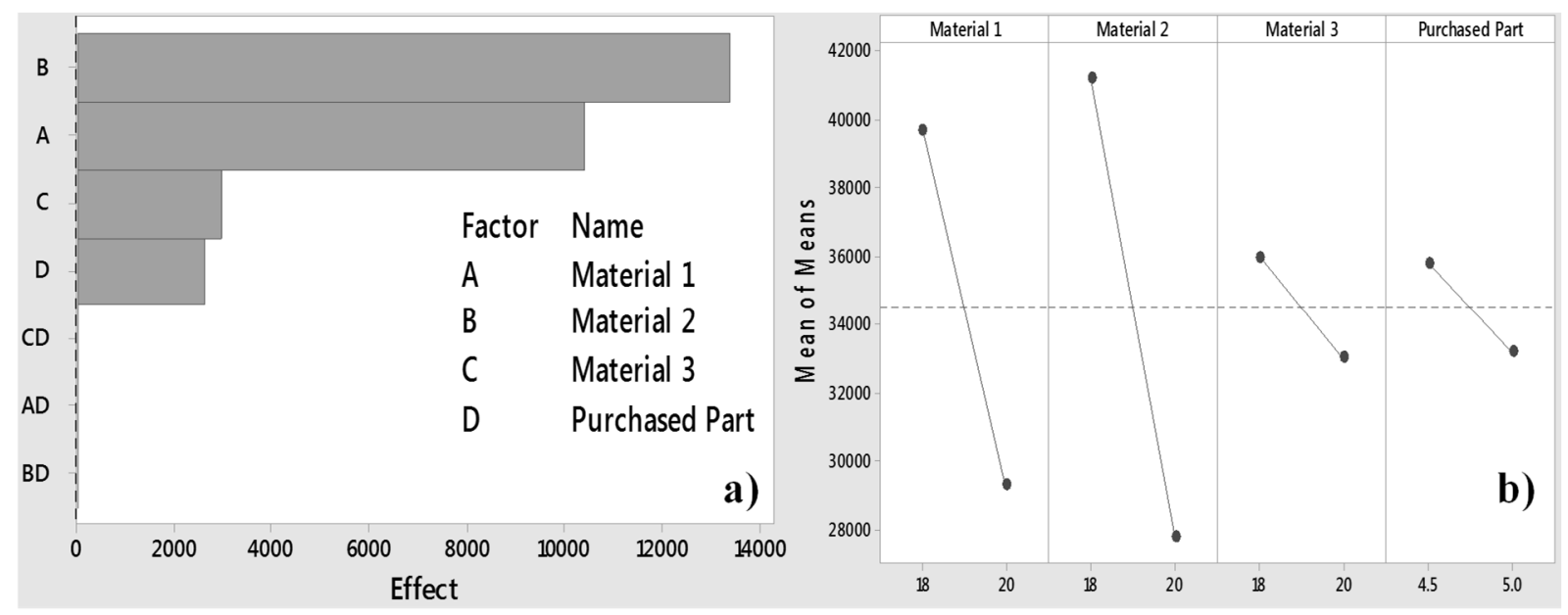

Figure 4 - Pareto chart and main effects plots varying raw material and purchased part inputs.

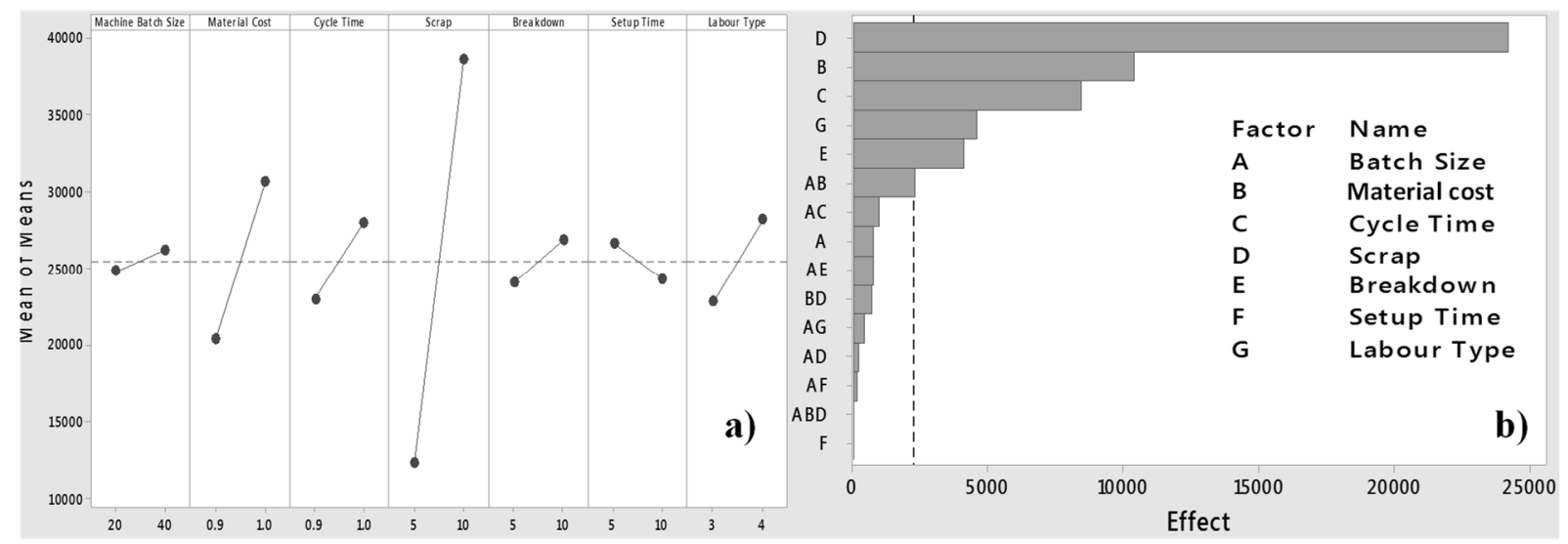

Figure 5 - Pareto chart and main effects plots varying production inputs. 

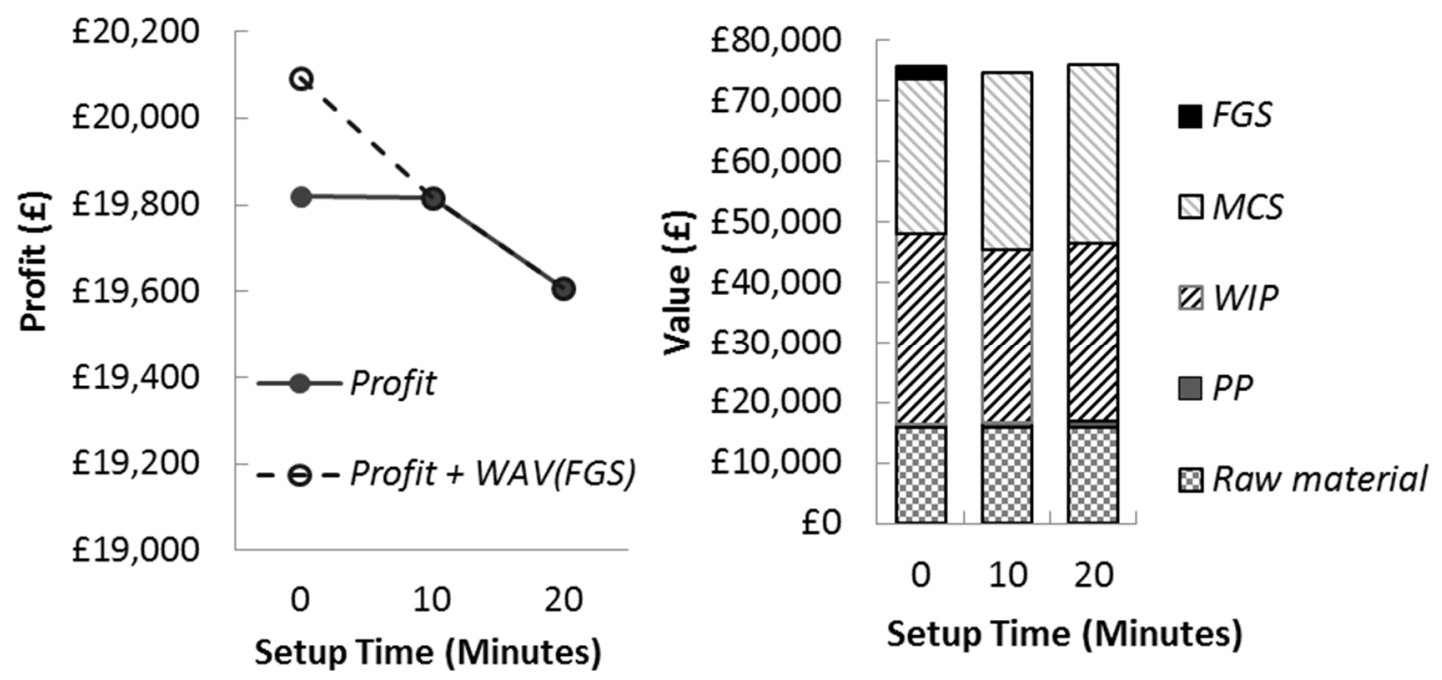

Figure 6 - Predicted Profit and end of period Weighted Asset Values with varying Setup Times. 


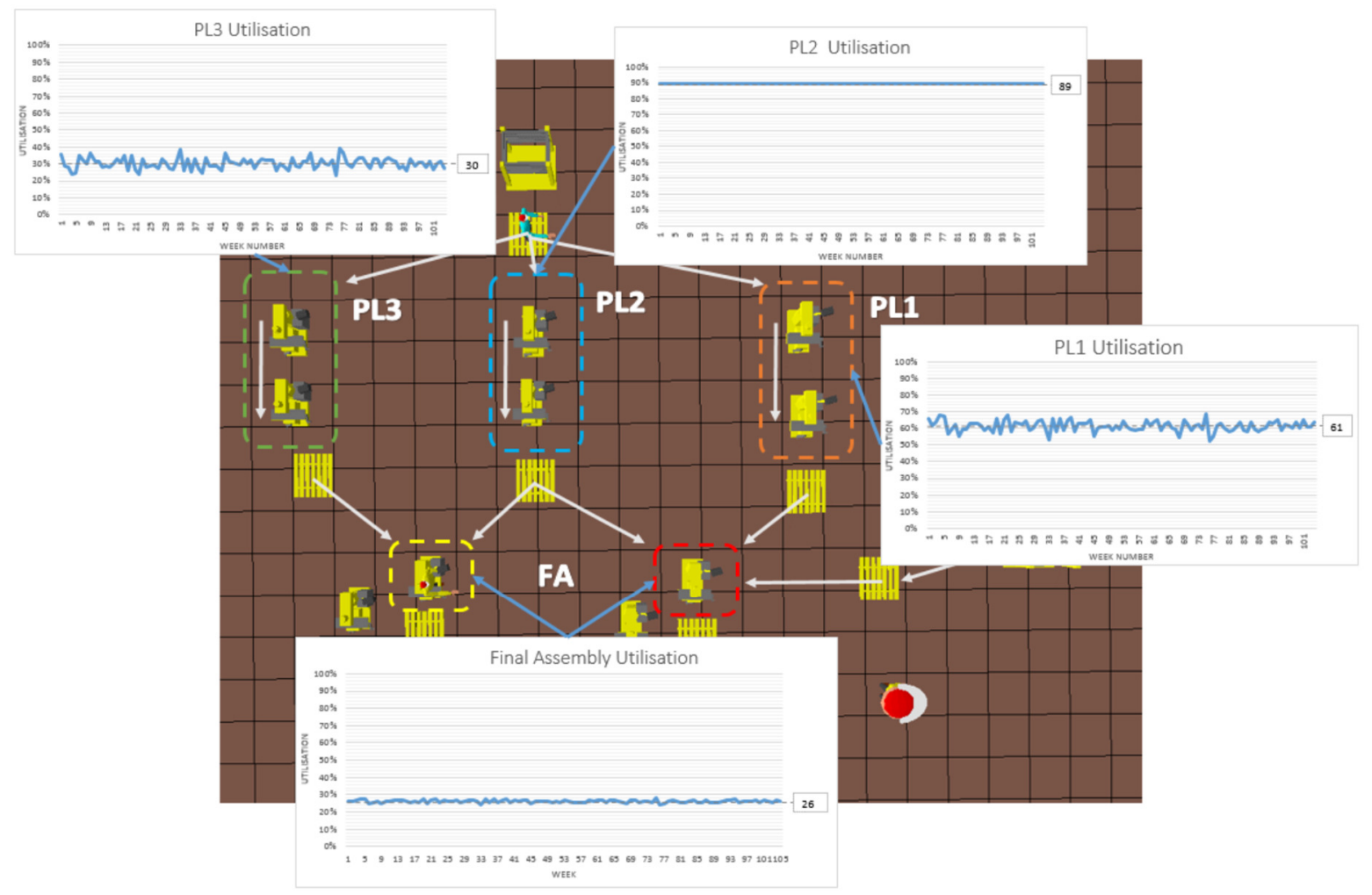

a)

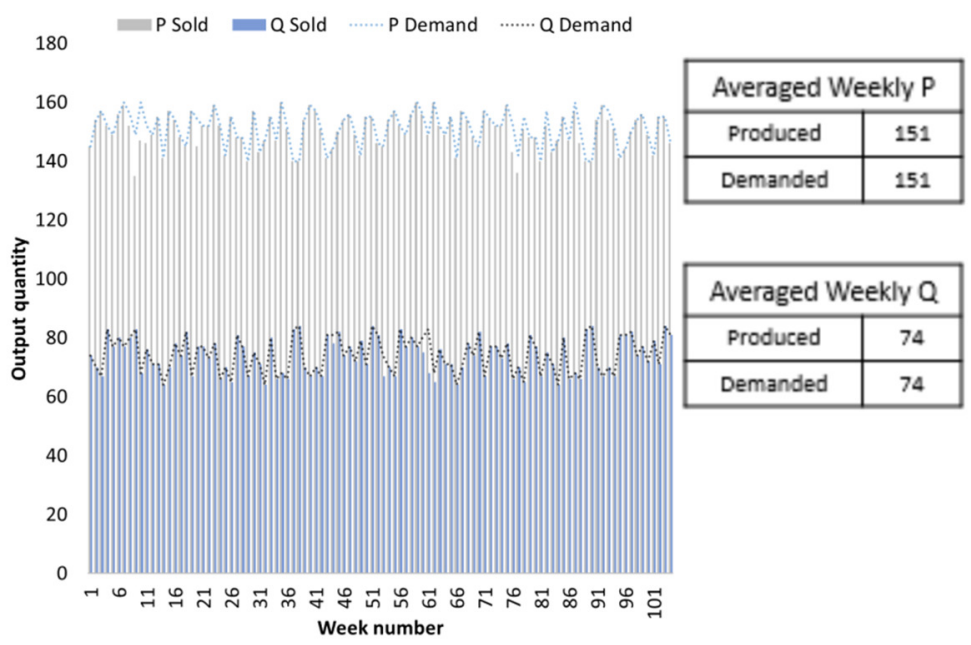

b)

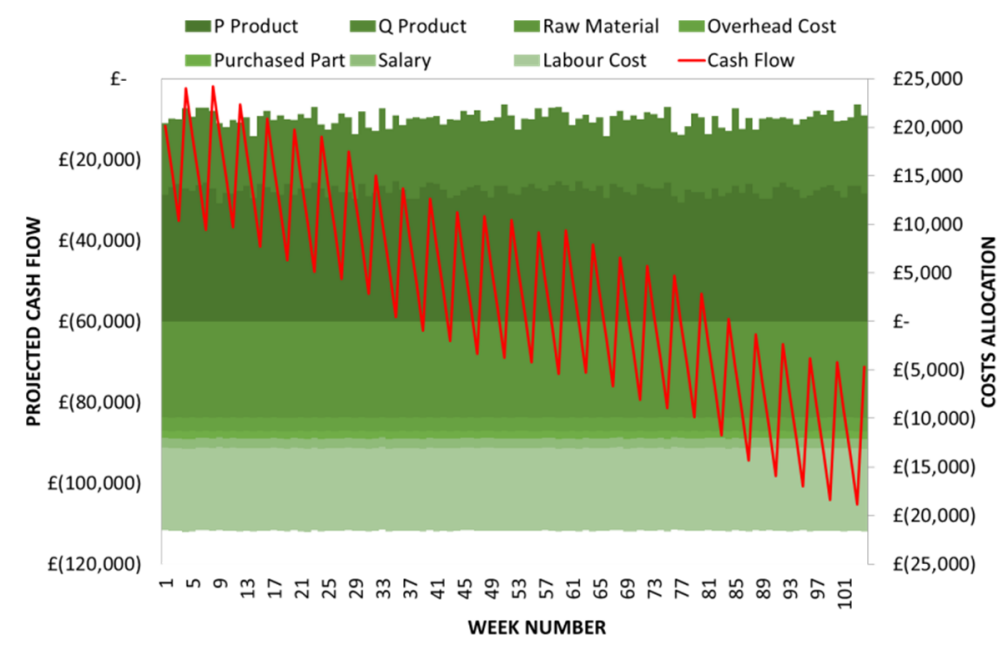

c)

Figure 7 - Dedicated operators on each work-station: (a) illustrates work-station and operator utilisation; (b) documents the units produced along with the units demanded; (c) plots the resulting system finances including the cash flow. 


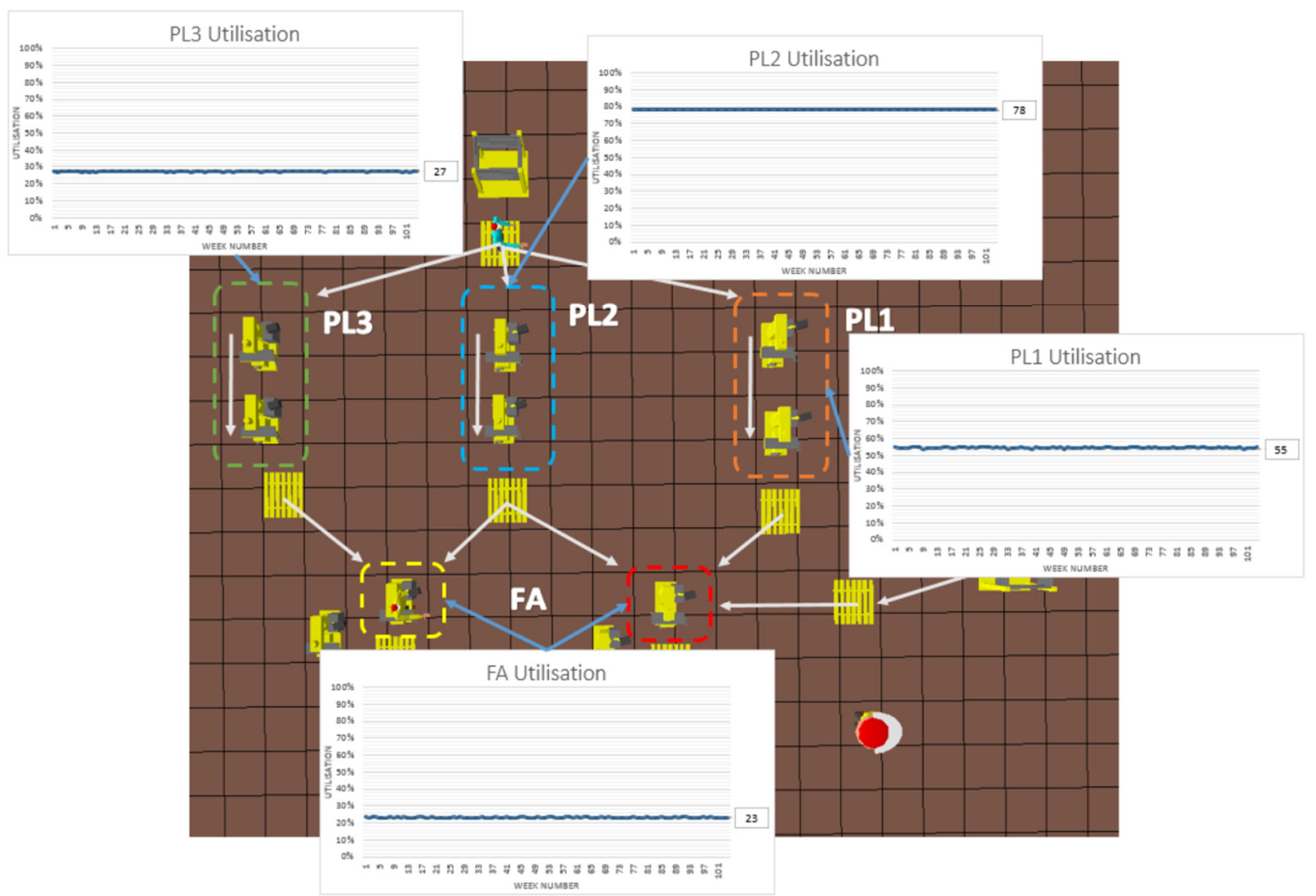

a)

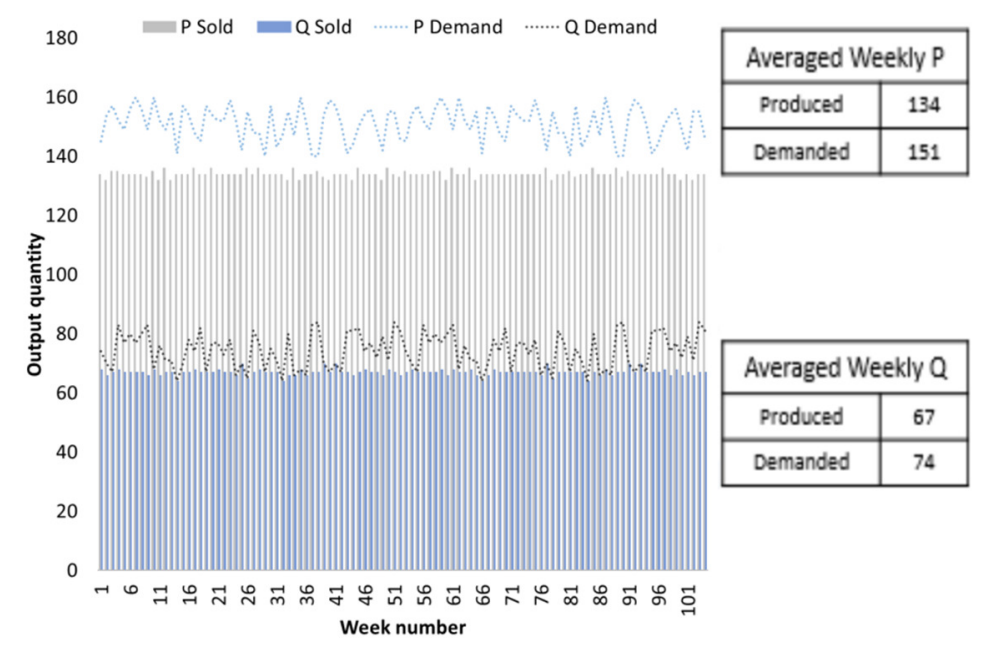

b)

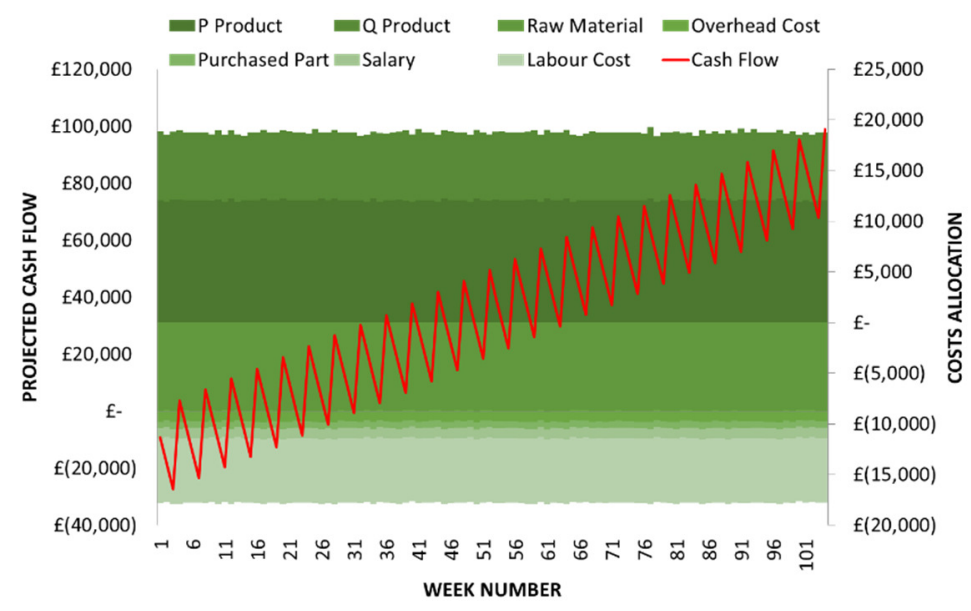

c)

Figure 8 - Shared operator on PL1 and PL3 (three dedicated operators): (a) illustrates work-station and operator utilisation; (b) documents the units produced along with the units demanded; (c) plots the resulting system finances including the cash flow. 


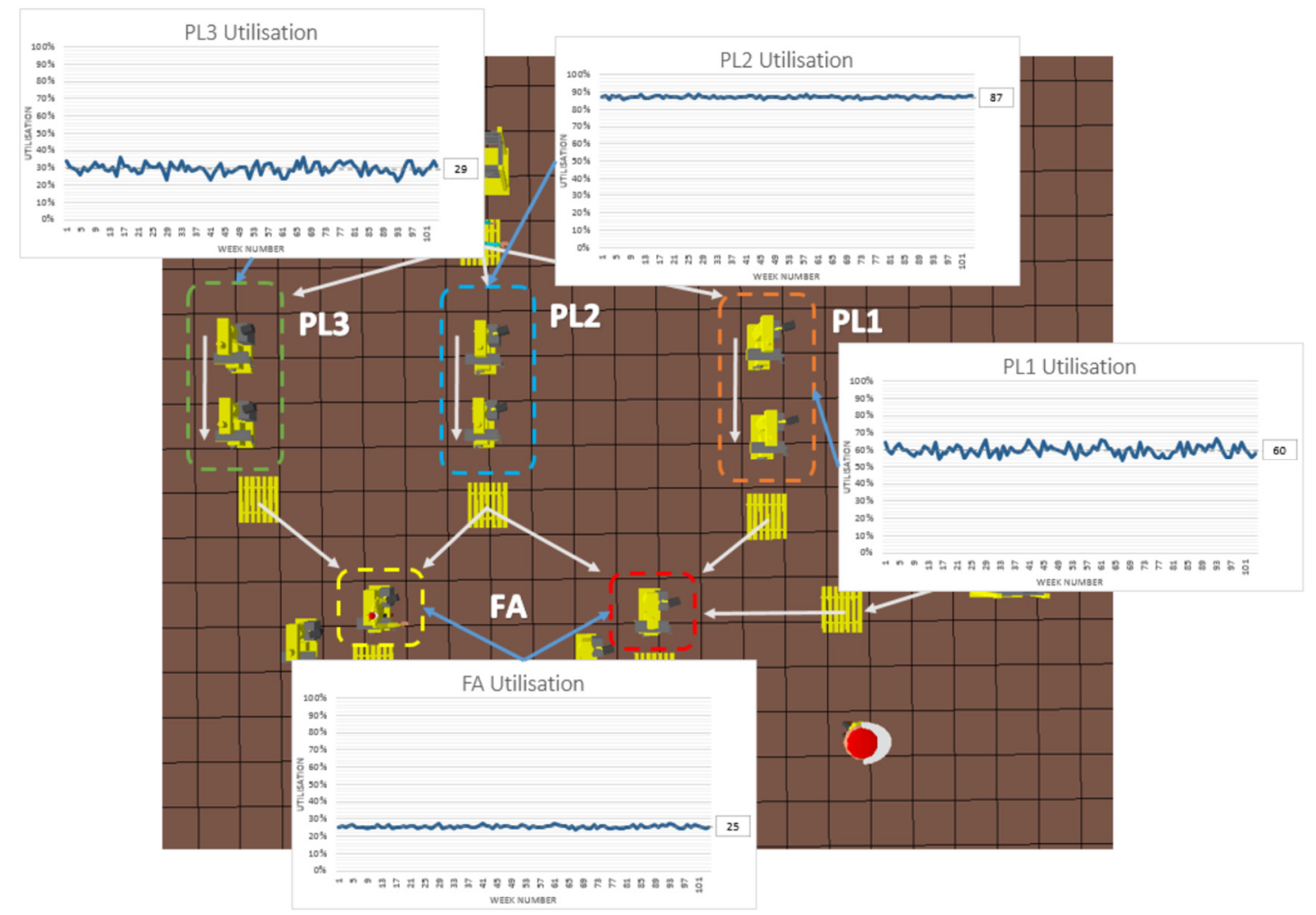

a)

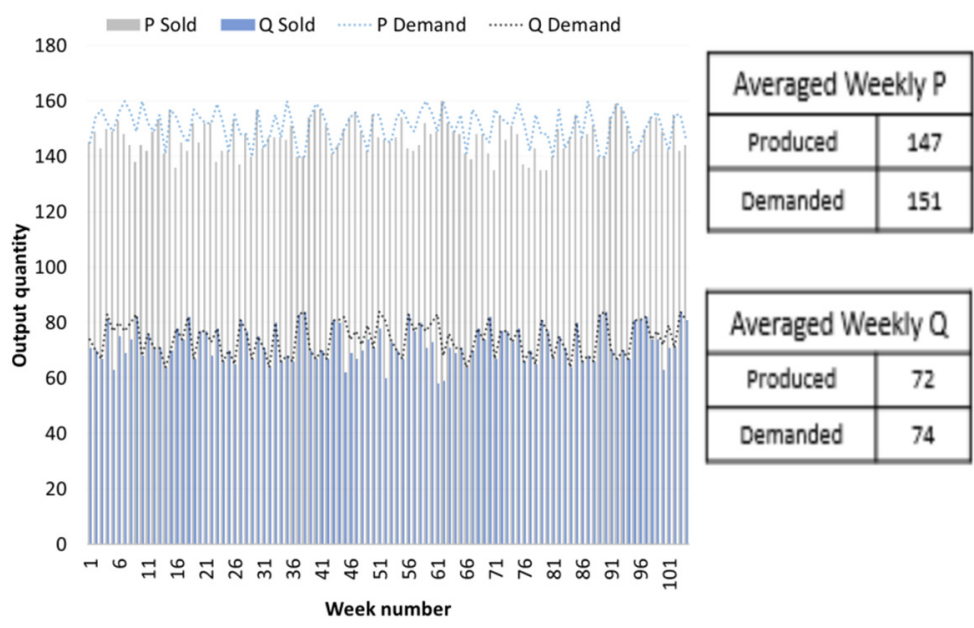

b)

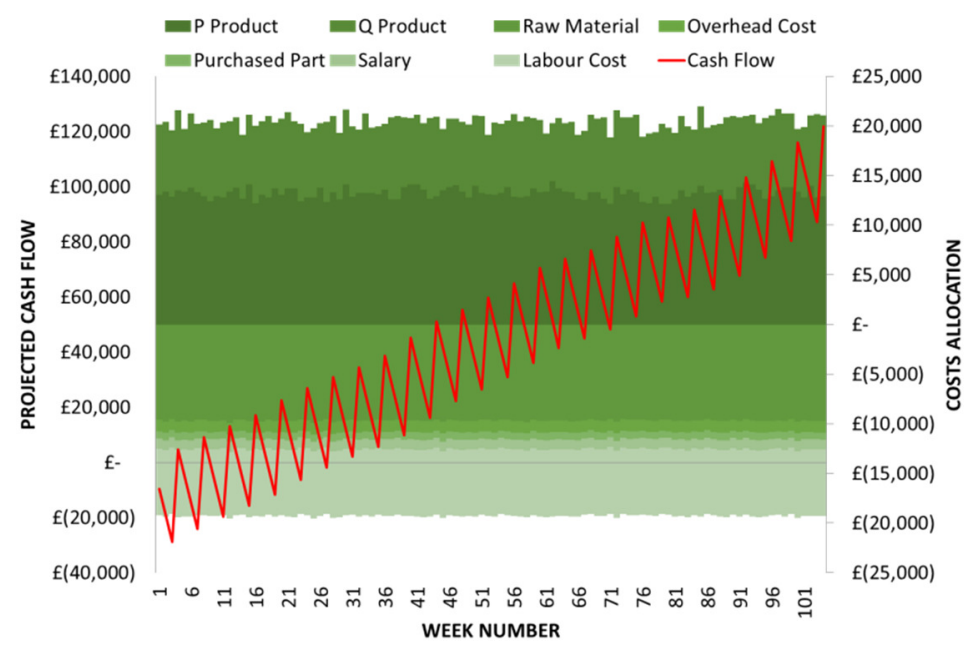

c)

Figure 9 - Three floating operators: (a) illustrates work-station and operator utilisation; (b) documents the units produced along with the units demanded; (c) plots the resulting system finances including the cash flow. 


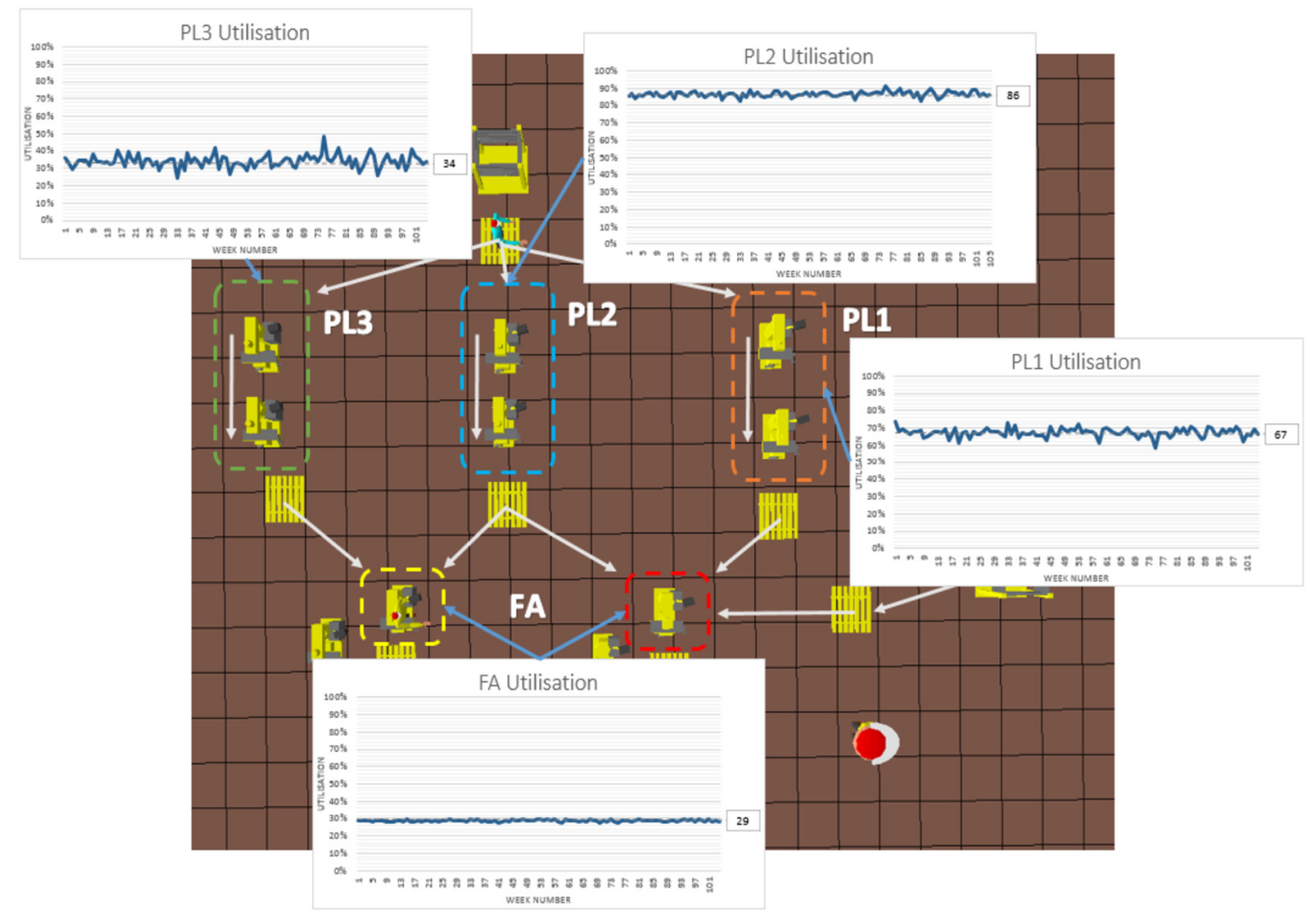

a)

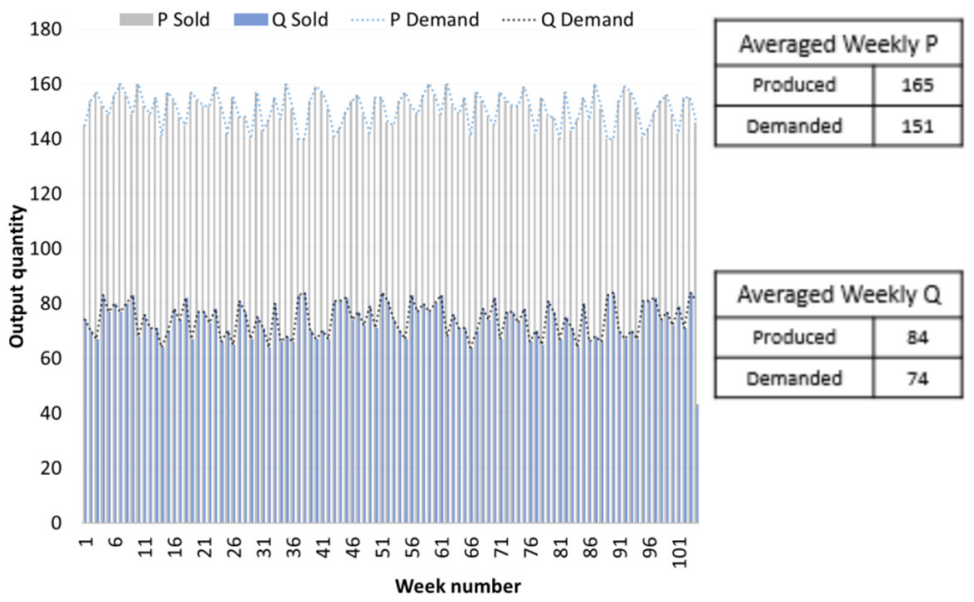

b)

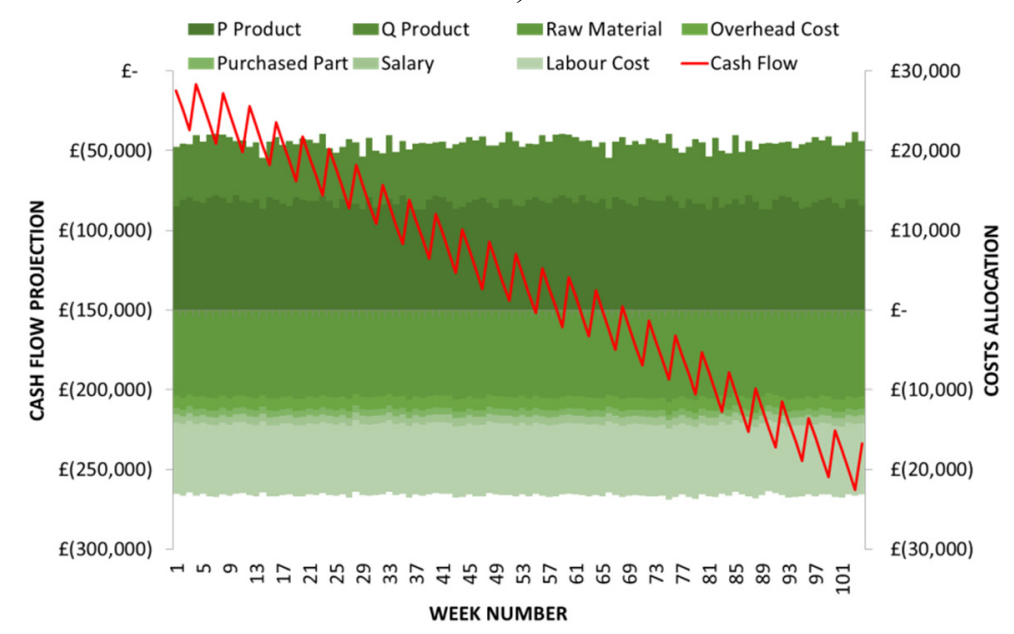

c)

Figure 10 - Four floating operators: (a) illustrates work-station and operator utilisation; (b) documents the units produced along with the units demanded; (c) plots the resulting system finances including the cash flow. 


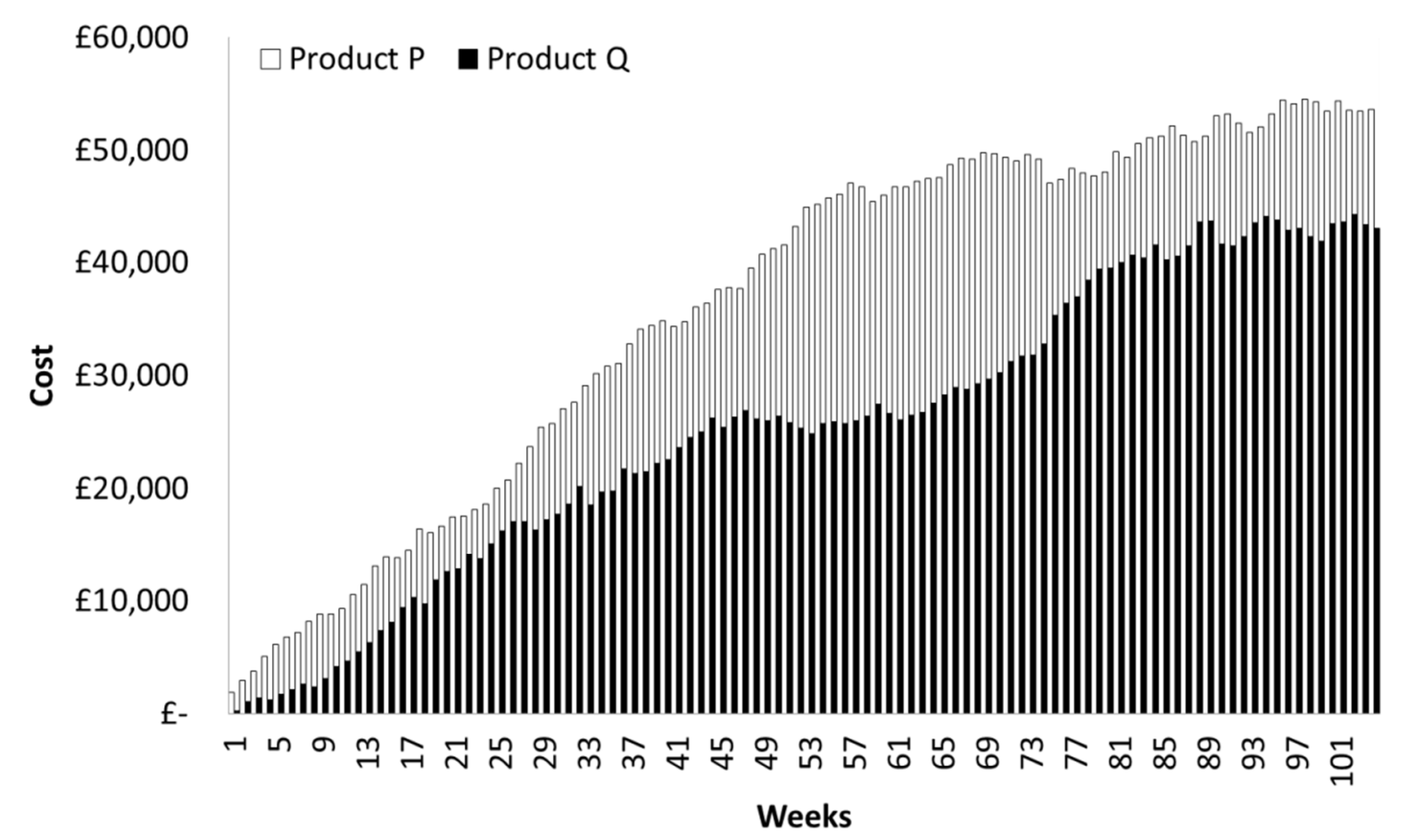

Figure 11 - FGS inventory with four floating operators. 
-FGS buffer limit - $25 \%$ of preceding week demand (for both Ps \& Qs)

--- FGS buffer limit - 35\% of preceding week demand (for both Ps \& Qs)

--- Two weeks of reducing stock in FGS (either Ps or Qs)

— One week of reducing stock in FGS (either Ps or Qs)

- Demand greater than the production of the preceding week (either Ps or Qs)

---- Demand greater than the production of both the last two preceding weeks (either Ps or Qs)

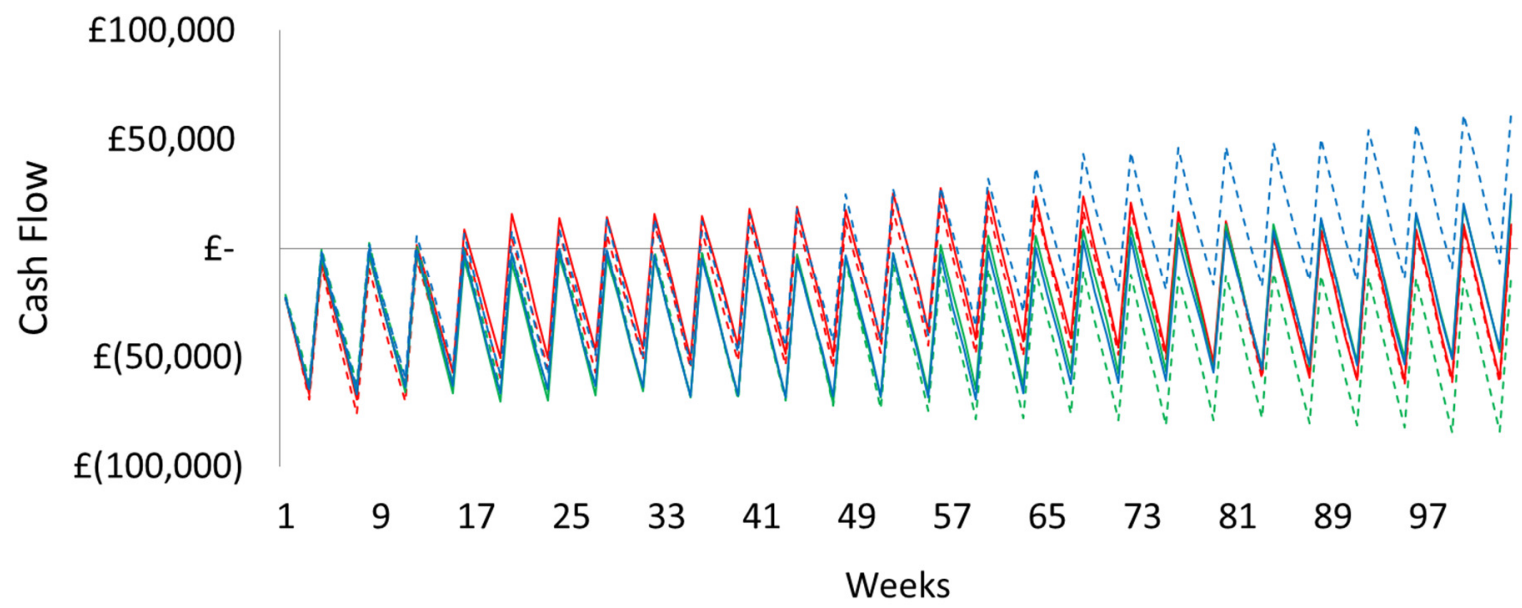

a)

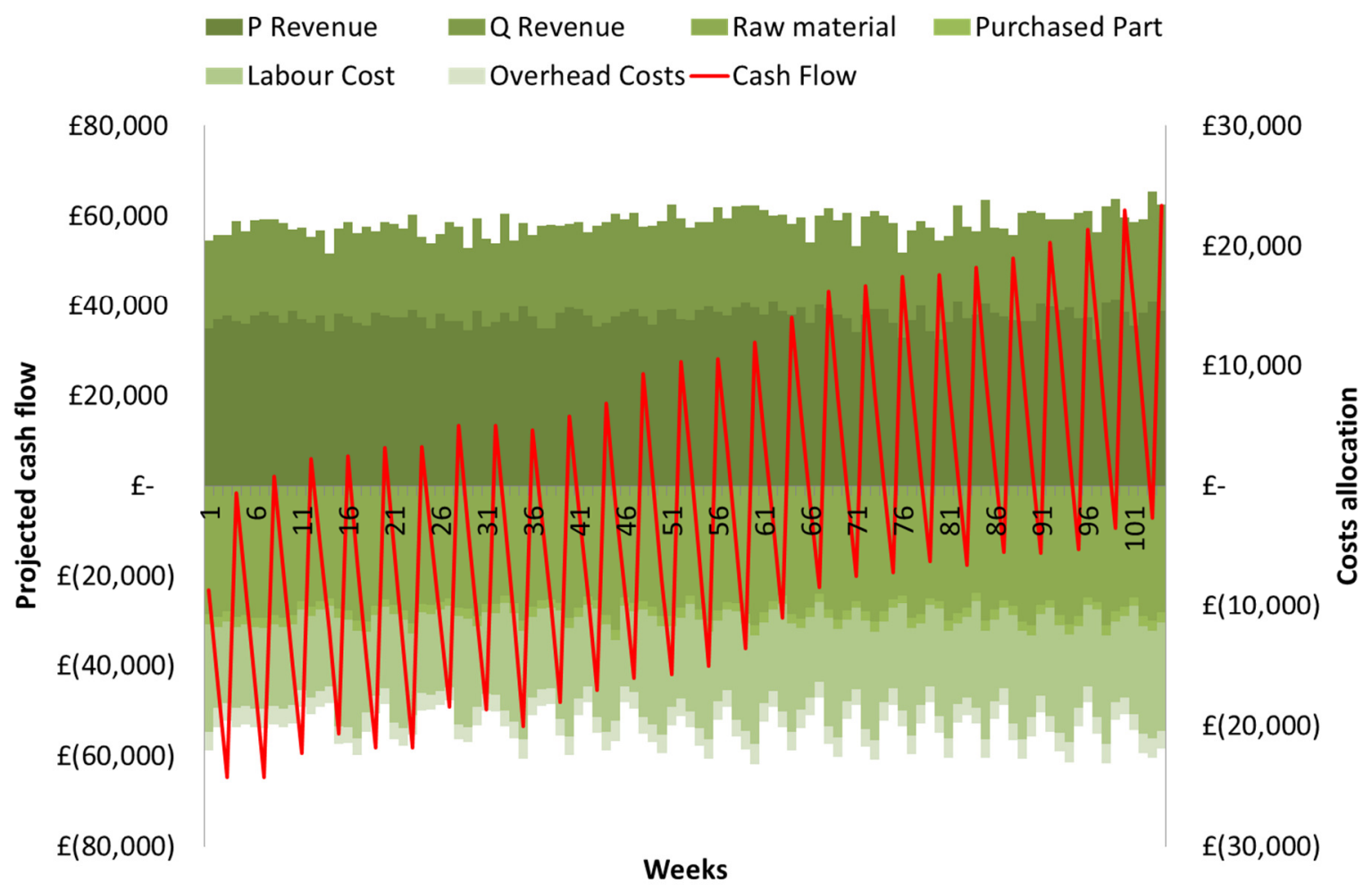

b)

Figure 12 - Control strategy assessment; a) cash flow for all strategies; b) cash flow and cost allocation for best strategy (Demand greater than the production of both the last two preceding weeks (either Ps or Qs)). 